\title{
RFID Teknolojisi ve Kullanım Alanları
}

\author{
Fatih MARAŞLI ${ }^{1 *}$, Musa ÇIBUK ${ }^{2}$ \\ ${ }^{1}$ Bitlis Eren Üniversitesi, Ahlat Meslek Yüksekokulu, Bitlis, Türkiye \\ ${ }^{2}$ Bitlis Eren Üniversitesi, Mühendislik Mimarlık Fakültesi, Bitlis, Türkiye
}

\begin{abstract}
Özet
RFID (Radyo Frekansı ile Tanımlama) teknolojisi, kablosuz iletişim teknolojilerinde gelişimini hızla sürdüren ve birçok sektörde uygulanabilen bir teknolojidir. Bu teknoloji temel olarak okuyucu, etiket ve bunlara bağl1 antenlerden oluşur. Radyo frekansı aracılığı ile etiketten bilgi okunur veya yazılır. Bu şekilde nesnelere yerleştirilen ya da taşınabilir etiketler sayesinde birç̧ok alanda bilgi saklama, kontrol ve takip işlemi gerçekleştirilir. RFID teknolojisi diğer kablosuz teknolojilerle entegre çalışabilme imkânı verebilir. Gelişimine bakılırsa, geleceğe dair umut vadeden bir teknolojidir. RFID başta tedarik zincirleri olmak üzere, sağlık, hayvancilık, eğitim, kütüphane, güvenlik vb. birçok alanda uygulanabilir bir teknolojidir. Bu çalışmada, RFID teknolojisinin yapısı, gelişimi ve yaygın kullanım alanları hakkında bilgi verilmiştir. Buna ek olarak RFID bileşenlerinin sektörel olarak kullanım raporları sunulmuştur.
\end{abstract}

Anahtar Kelimeler: RFID, Kablosuz Teknolojiler, RFID Kullanım Alanları

\section{RFID Technology and Application Areas}

\begin{abstract}
RFID (Radyo Frequency Identification) technology, which continues to grow rapidly in wireless technology, can be applied in many sectors. Basically this technology consists of the reader, the tag and the antenna. The information from the tag is read or written via the radio frequency. In this way, with the help of the tags placed on the objects, information storage, control, and the tracking operation is performed in many areas. RFID technology can give opportunity to integrate with other wireless technologies. Considering the development, it is seen as a promising technology for the future. RFID is a technology that can be applied in many areas such as supply chains, health, animal husbandry, education, library, security. In this paper, it has been informed about the structure of the RFID technology and the development and widespread usage. In addition, usage reports has been presented of the sectorally use of RFID components.
\end{abstract}

Keywords: RFID, Wireless Technologies, RFID Application Areas

\section{Giriş}

Kablosuz teknolojiler günlük hayatımızda büyük öneme sahiptir. En temel olarak kablosuz iletişimde WiFi (Wi-Fi Alliance, tarih yok), Bluetooth [2], NFC (NFC Forum, tarih yok), IrDA (Knutson) ve ZigBee [5] gibi teknolojiler birçok alanda kullanılmaktadır. Günümüzde kullanımı hızla artan akıllı telefonlar sayesinde, bu teknolojiler birçok kullanıcıya ulaştırılmış durumdadır. Dosya gönderimi/alımı, görüntülü konuşma, cihaz paylaşımı ve daha birçok uygulama kablosuz sistemler aracılığıyla kullanımı mümkündür.

Kablosuz sistemlerin bu gelişimi, savaş teknolojileri [6], bilgi gizliliği gerektiren uygulamalar [7], üretim faaliyetleri gibi alanlarda da büyük yer bulmuştur. 20. yüzyıl ortalarında yine savaş teknolojisinde kullanılmak için geliştirilen RFID teknolojisi de kablosuz sistemlerde yerini almıştır.

\footnotetext{
*Sorumlu Yazar: fmarasli@beu.edu.tr
} 
Fiziksel nesneleri tanımlamak için geliştirilen bu teknolojinin hızlı gelişimi üretim faaliyetinde bulunan şirketlere de önemli avantajlar sağlamıştır. Bugün gelişerek büyüyen RFID sistemi üretim faaliyetleri ve tedarik zincirlerinde maliyet, üretim süresi gibi önemli kriterler açısından tercih edilen bir teknoloji olmuştur. Barkod teknolojisine göre birçok alanda kullanılabilecek yeni bir teknolojidir. RFID teknolojisinin geliştirilebilir, birçok alanda kullanılabilir, esnek, güvenilir ve ucuz olmasından dolayı bu teknolojinin kullanım alanları bu çalışmada ayrıntıları ile irdelenmiştir.

\section{RFID Teknolojisi Nedir?}

RFID, Radyo Frekansı ile Tanımlama olarak adlandırılır. Yani RFID’yi oluşturan bileşenler radyo frekansı ile haberleşmektedir. RFID; okuyucu, etiket ve anten olmak üzere 3 temel bileşenden oluşur. Okuyucular; nesnelere yerleştirilmiş etiketler sayesinde nesneye ait bilgileri, radyo dalgalarını kullanarak sayısal bir kod şeklinde alan bileşenlerdir. Etiketler, bilgileri saklayan bileşenlerdir. Etiket ve okuyucu arasındaki iletişim antenler aracılığı ile gerçekleşir ve buna bağlama (coupling) adı verilir. Okuma mesafesini genişletmek için ekstra antenler kullanılabilir. RFID’nin temel çalışma prensibi Şekil 1'de gösterilmiştir.

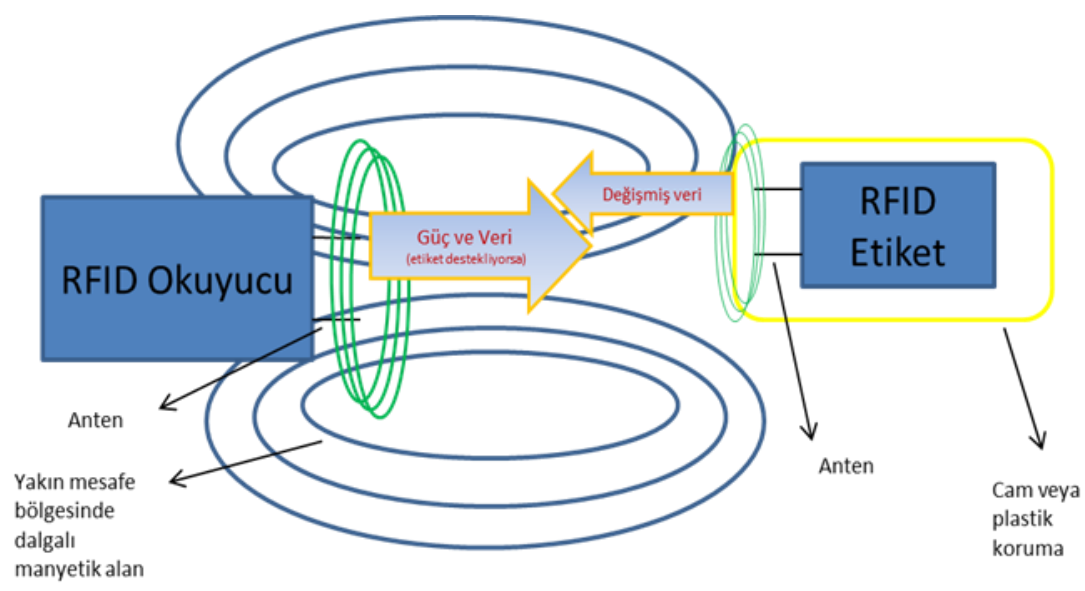

Şekil 1. Yakın alanda $100 \mathrm{Mhz}$ 'den daha düşük frekanslarda etiketlerin güç/iletişim mekanizması [8]

RFID sistemlerinde bağlama iki türlü gerçekleşebilir: Elektromanyetik veya manyetik [9]. Hangi yöntemin kullanılacağı; etiket maliyeti, büyüklüğü, okuma hızı ve uzaklığı gibi uygulama gereksinimlerine bağlı olarak belirlenir. Manyetik bağlama, genelde kısa mesafe RFID sistemlerinde giriş kontrol uygulamalarında [10] kullanılır. Elektromanyetik bağlama ise etiket ve okuyucu arasındaki veri iletişiminde kullanılan en yaygın bağlama türüdür. Bu yöntemde okuyucunun yaydığı elektromanyetik dalgalar antenle buluşmakta ve etiket içindeki devreleri harekete geçirmektedir. Etiketin içinde yer alan kondansatör, okuyucudan gelen dalgalardaki enerjiyi alır, mikroçip bu enerjiyi kullanarak dalgaları okuyucuya geri gönderir ve okuyucu da yeni dalgayı dijital veri haline dönüştürür ve okuma işlemi gerçekleşmiş olur.

RFID, Auto-ID (Automatic Identification - Otomatik Tanımlama) Grubunun bir parçasıdır. Auto-ID genellikle otomatik veri toplama ile birlikte anılır. Diğer bir deyişle; varlıkları tanımlamayı, onlar hakkında bilgi toplamayı ve toplanan bilgileri el ile saymadan bilgi teknolojileri ortamında hızla değerlendirmeyi ifade eder [11]. Auto-ID Grubunun çalışma alanı Şekil 2'de gösterildiği gibi 
barkodlar, sesli tanımlama, optik karakter tanımlama, biyometrik tanıma, akıllı kartlar ve RFID'dir [12].

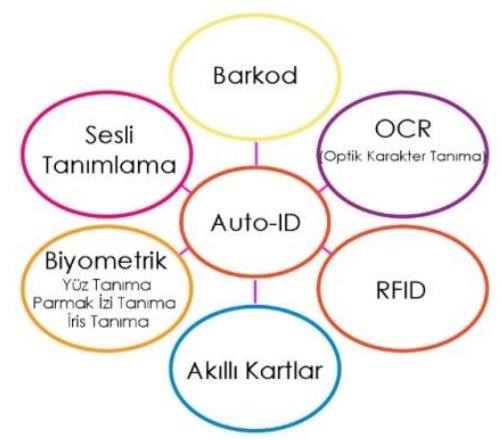

Şekil 0. Auto-ID grubu çalışma alanları

\section{RFID Tarihçesi}

RFID içerikli kilometre taşı sayılabilecek ilk çalışma Harry Stockman tarafindan Ekim 1948'de "Communication By Means of Reflected Power" [13] adıyla yayınlanmıştır. Stockman makalesinde, "Bu konuda araştırma ve geliştirme işlemleri yapılmadan önce yansımalı güç iletişiminin bazı temel problemleri çözülmelidir” demiştir. Stockman'ın bu makalesi 30 yıl sonra daha değerli hale gelmiştir. Bunun yanında transistör, entegre devreler, mikro işlemciler, iletişim ağ araçları gibi gelişmelere de ihtiyaç duyulmuştur.

1930 ve 1940 y1llarındaki radar ve radyo hakkındaki gelişmelerden sonra 1950'li yıllarda RFID için tam bir çığır açılmıştır. Havacılıkta RFID'nin kullanılması ile IFF (Identification Friend or Foe - Dost veya Düşman Tanımlaması) uçakları ayırmaya yarayan uygulamalarıyla birçok teknolojiler keşfedilmeye başlanmıştır [14].

1970'li yılların başında Sensormatic ve Checkpoint şirketleri özellikle hırsızlığa karşı geliştirilen EAS (Electronic Article Surveillance - Elektronik Eşya İzleme) adlı ilk ticari uygulamalarını piyasaya sunmuşlardır [15]. Malzeme ve ürünlerin elektronik olarak izlendiği EAS sistemlerinde, 1 bit etiketler kullanılmakta ve sistem sadece ürün/malzeme üzerinde etiketin var olup olmadığını kontrol ederek uyarı sinyali vermektedir. Özellikle giyim mağazalarında ve kütüphanelerde hırsızlığa karşı kullanılan, pil içermeyen, ucuz ve basit pasif etiketler içeren EAS sistemler, bugünkü RFID uygulamalarının temelini oluşturmuştur.

1980'li yıllarda RFID uygulamaları birçok alana yayılmıştır. Avrupa'da hayvan izleme sistemleri çok yaygınlaşmış, aynı zamanda İtalya, Fransa, Portekiz ve Norveç gibi ülkelerde ücret geçişli yollar RFID ile donatılmıştır [16].

1990'lar RFID için kayda değer bir dönemdir. Oklahoma'da 1991'de açılan ücretli geçiş sistemi araçlara gişelerden duraklamadan hızlıca geçiş imkânı tanımıştır [16].

Gelişmeler 1990'larda entegre devrelerin geliştirilmesi ile RFID etiketlerinin bir tek entegre devre boyutuna küçültülmesine kadar devam etmiştir. Bununla birlikte frekans spektrum tahsisinde devletlerarası standartlar belirlenmiştir [17].

2000'li yıllarda minyatür boyutlarda RFID'ler üretilmeye başlamıştır. Küçülen RFID'ler birçok sisteme dâhil edilebilir hale gelmiştir. RFID bileşenlerinin maliyeti düşmüştür. Özel anahtarlama ve kodlama sistemleri geliştirilmiştir. $\mathrm{Bu}$ y1llarda büyük perakende zincirleri ve DoD (Department of Defense) gibi Amerikan Hükümet kuruluşları, tedarikçilerine RFID sistemlerini kullanmaları için yaptırım kararları almaya başlanmıştır. Aynı yıllarda MIT (Massachusetts Institute of 
Technology) Üniversitesi'nde bulunan Auto-ID Laboratuvarı'nın girişimiyle Elektronik Ürün Kodu (EPC-Electronic Product Code) standartlarının gelişmesi için çalışmalar hızlanmıştır. Tedarik zincirinde uluslararası standartların belirlenmesinde faaliyet gösteren GS1 (Global Standardization) kuruluşu, MIT, Cambridge, St. Gallen Üniversiteleriyle işbirliği yaparak EPCGlobal Organizasyonunu kurmuştur. Kâr amacı gütmeyen bu kuruluş, RFID standartlarının geliştirilmesi için faaliyet göstermektedir. EPC sisteminde her ürün, RFID etiketinde bulunan tekil bir numara ile izlenebilmekte, internet üzerindeki DNS (Domain Name System) yapısına benzer bir yapı olan ONS (Object Naming Service) ile EPCIS (EPC Information Service) ağ sistemi üzerinden ürün bilgilerine dünyanın her yerinden ulaşılabilmektedir [18].

Tek bir CMOS entegre devre ve bir antenden oluşan daha küçük mikrodalga etiketlere geçiş yapıldıktan sonra etiketler cama veya nesnelere yapışacak şekilde üretilmeye başlanmıştır. RFID ile elektronik ödeme işlemleri Amerika'da yaygınlaşmış ve Federal İletişim Komitesi (FCC) 5,9 Ghz geniş bant aralığını RFID için ayırmıştır. Taşımacılık zinciri ve eşya taşımacılığı 1990'ların sonundaki hızlı gelişim süreciyle RFID uygulamalarının bir alanı haline gelmiştir. MIT'de; RFID hakkında gelişme, üretim standardı, performans araştırmaları ve bilgi paylaşımı için Auto-ID merkezi açılmıştır. EPC Global, RFID uygulama alanlarında standart geliştirme işini kendi üzerine almış ve bununla birlikte ISO tarafından birçok standart ortaya konulmuştur [19].

Sonuç olarak RFID'nin radar olarak II. Dünya savaşıyla başlayan asıl serüveni bugün farklı noktalara gelmiş ve günümüzde gelişimini ve değişimini sürdürmeye devam etmektedir.

\section{RFID Sisteminin Bileşenleri}

RFID'yi özetlemek gerekirse, içeriğinde nesneye ait bilgiler bulunduran bir mikroçipe sahip olan, bu mikroçipe bağlı bir antenle takip ve analiz yapabilen ve nesnelere entegre edilebilen bir etiket kullanarak radyo frekansları aracılığıyla veri alışverişi sağlayan otomatik tanımlama ve izleme sistemidir. Bu bilgi alışverişinde rol oynayan 3 temel bileşen vardır. Okuyucu, etiket ve antendir. Okuyucunun yaydığı elektromanyetik dalgalar etiketin antenine ulaşır. Bu dalgalar etikette bulunan mikroçipteki devreleri harekete geçirir ve mikroçip dalgaları modüle ederek anteni aracıllğı ile okuyucuya geri gönderir. Okuyucuya gelen bilgi dijital bir şekle dönüştürülerek görüntülenir. Sistemde bulunan bilgilerin bilgisayar ortamında saklanmasinda rol oynayan ve ara katman yazılımıyla iletişimde olan denetleyiciler vardır. Buradan yola çıkarak sistemin tamamında işlevi olan birimleri donanımsal olarak: RFID Etiket, RFID Anten ve RFID Okuyucu, yazılımsal olarak: Denetleyici, Arakatman Yazılımı ve EPC Kodu listelenebilir.

\subsection{RFID Etiketler}

Etiket, içinde nesneye ait bilgilerin depolandığı bir yonga (çip seti) ve okuyucu ile iletişime geçebilmek için bir anten barındıran bileşenlerdir. Okuyucu ile iletişime geçebilmek için RF sinyallerini kullanırlar. Etiketlerin yüzeyleri farklı türde malzemelerle kaplanabilir. Her etiketin benzersiz bir tanımlayıc1 (id) numarası vardır. Etiketlerin hafıza kapasiteleri 64 bit - $8 \mathrm{MB}$ arasında değişebilir. RFID etiketler okuyucu ile temas etmeden iletişime geçebilirler. RFID etiket seçiminde dikkat edilecek noktalar aşağıdaki gibidir.

- Etiketleme yapılacak yüzey, metal, plastik, tahta vb.

- İstenilen okuma mesafesi

- Etiket boyutunun büyüklüğü 
- Çevresel koşullardaki aşırılık (aşırı sıcak, soğuk, nem vb.)

- Etiketin eklenme yöntemi (yapıştırarak, perçinleyerek, kablo bağlantıları vb.) [20].

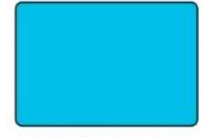

ALT TABAKA

PVC

PET

Kağıt

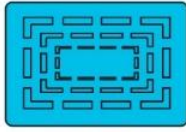

ANTEN

Bakır

ALU

lletken Bağ
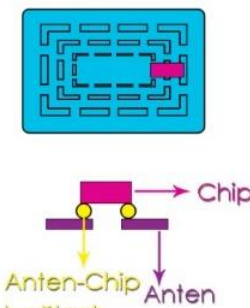

bağlant

noktası

Şekil 3. Etiket İç Yapısı [21]

Etiket yapısının katmansal hali Şekil 3'de gösterilmiştir.

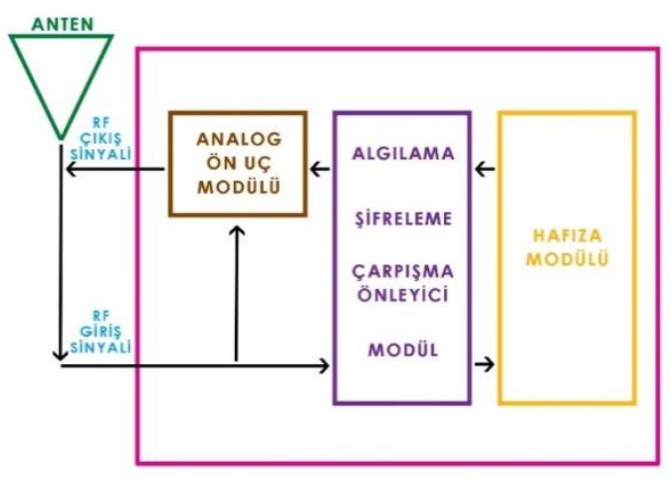

Şekil 0. RFID Etiket(pasif) Mimarisi [22]

Bir etiketin içyapısı Şekil 4'de gösterilmiştir. Genel olarak RFID etiketlerinin içyapısı şu birimlerden oluşur.

- Kodlama/Kod çözme

- Hafiza

- Anten

- Güç ünitesi (Aktif Etiketlerde bulunur)

- İletişim Kontrol Birimi [7]

Günümüzde kullanılmakta olan etiketlere örnekler Şekil 5’te gösterilmiştir. 


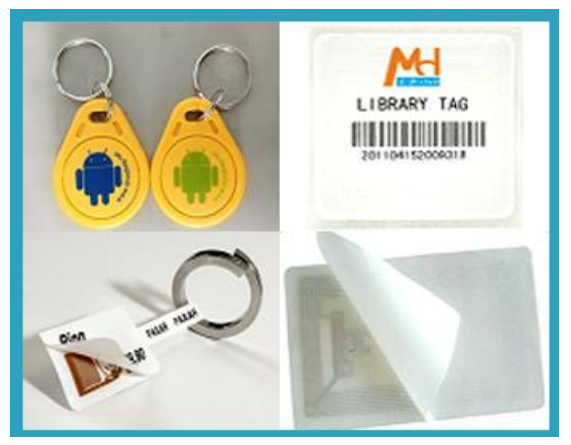

Şekil 5. Etiket Örnekleri [23]

Etiketlerin kategorilere göre dağılımı Şekil 6' da gösterilmiştir.
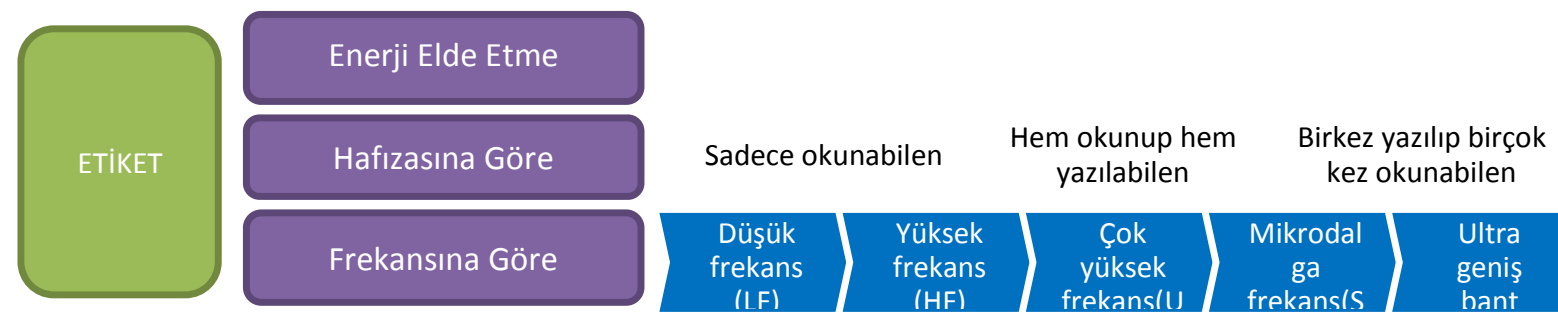

Şekil 6. Etiket Türleri

\subsubsection{Enerji Elde Etme Yöntemine Göre Etiketler}

Etiketler, okuyucu ile iletişime geçebilmek için enerjiye ihtiyaç duyarlar. Bu enerjisini ya okuyucudan alırlar ya da kendi üzerlerinde bir güç kaynağı barındırırlar. Bu enerjiyi elde etme yöntemleri etiket seçiminde önemlidir. Çünkü okuma mesafesi, kullanım ömrü, maliyet gibi etkenler bu etiketlerde farklılık gösterir. RFID etiketler enerji elde etme yöntemine göre 3'e ayrılır.

\subsubsection{Pasif RFID Etiketler}

Kendilerine ait bir güç kaynakları yoktur. Okuyucu ile ilk iletişime geçme konusunda pasiftirler. $\mathrm{Bu}$ yüzden kendi çiplerini harekete geçirme konusunda ve iletişime geçme konusunda tamamıla okuyucuya bağımlıdırlar. Gerekli enerjiyi radyo sinyalleri aracılığı ile okuyucudan alırlar. Okuyucudan gelen bu enerji etiket anteninde bir gerilim indüklemesi oluşturarak etiketin çipini harekete geçirir. Çip içinde barındırdığı bilgiyi yine anteni aracılığı ile okuyucuya gönderir. Pasif etiketler maliyetleri düşük olduğu ve birçok sektörde yeterli geldiği için kullanım alanı fazladır. Diğer etiketlere göre dezavantajı çevresel koşullardan etkilenme oranı yüksektir.

\subsubsection{Yarı pasif RFID Etiketler}

$\mathrm{Bu}$ etiketler kendi çiplerine üzerinde barındırdıkları güç kaynağı ile enerji sağlarken, okuyucu ile iletişime geçme konusunda pasif etiket gibi okuyucuya bağımlıdırlar. Okuyucu tarafından sorgulanmadan harekete geçmezler. Pasif etikete göre daha uzak mesafelerde iletişim sağlar ve maliyeti pasif etikete göre yüksektir. 


\subsubsection{Aktif RFID Etiketler}

Hem kendi çipleri için hem de okuyucu ile iletişime geçmek için enerjilerini kendi güç kaynaklarından sağlarlar. Yani okuyucunun sorgulamasını beklemeden doğrudan okuyucuya sinyal gönderebilir. Okuma mesafeleri uzun ve maliyetleri diğer etiketlere göre yüksektir.

Enerji elde etme yöntemine göre etiketlerin genel özellikleri Çizelge 1'de gösterilmiştir

Çizelge 1. Enerji Elde Etme Yöntemine Göre Etiketler [24]

\begin{tabular}{|c|c|c|c|}
\hline Etiket Tipleri $\Rightarrow$ & Pasif & Yarı Pasif & Aktif \\
\hline Güç Kaynağı & RF aracılığı ile okuyucudan alır & Batarya & Batarya \\
\hline İletişim & Sadece yanıt verir & Sadece yanıt verir & $\begin{array}{l}\text { Yanıt verir ve ilk iletişime } \\
\text { geçebilir }\end{array}$ \\
\hline Mesafe & $\begin{array}{l}\text { LF, HF: 0,2 m } \\
\text { UHF, SHF: } 3 \mathrm{~m} \\
\text { UWB: } 10 \mathrm{~m}\end{array}$ & $\begin{array}{l}100 \text { metreden daha uzak } \\
\text { mesafelerde }\end{array}$ & $\begin{array}{l}100 \text { metreden daha uzak } \\
\text { mesafelerde }\end{array}$ \\
\hline Maliyet & Ucuz & Pasiften pahalı & En pahalısı \\
\hline Örnek Uygulamalar & EPC, Yakın mesafe kartları & Elektronik geçiş, Palet izleme & $\begin{array}{l}\text { Büyük çapta mal izleme, } \\
\text { Hayvan takibi }\end{array}$ \\
\hline Etiket Örnekleri & & [25] & [26] \\
\hline
\end{tabular}

\subsubsection{Hafıza Yapısına Göre Etiketler}

\subsubsection{Sadece Okunabilen Etiketler}

$\mathrm{Bu}$ etiketlerin hafizası üretim esnasında programlanır, üretimden sonra değiştirilemez. Verileri depolama kapasitesi kısıtlıdır. Maliyetleri düşüktür. Ağırlıklı olarak pasif tipte olurlar [27].

\subsubsection{Hem Okunup Hem Yazılabilen Etiketler}

$\mathrm{Bu}$ tip etiketlerde okuyucunun kapsama alanındayken hem bilgi okunabilir hem de yazılabilir. $32 \mathrm{~KB}$ ile $128 \mathrm{~KB}$ aralığında değişebilen hafizaya sahiptirler. Maliyeti sadece okunabilen etiketlere göre yüksektir. Bu yüzden ucuz maliyet gerektiren sistemlerde kullanılmaz. Hem aktif hem pasif etiketlerde bulunabilir. Bu etiketlerde EEPROM, FRAM, SRAM gibi hafiza türleri kullanılır. 


\subsubsection{Bir Kez Yazlıp Birçok Kez Okunabilen (Worm) Etiketler}

Normal şartlarda sadece okunabilen etiketlere benzerdir. Asıl fark, sadece okunabilen etiketler rastgele ID'ler verilerek üretilirken, worm etiketlere tüketicinin talebine göre bilgi yüklemesi yapılır. Yine üretimden sonra bilgiler değiştirilemez. 128 bit $-1 \mathrm{~Kb}$ aralığında hafizaya sahiptirler.

\subsubsection{Frekanslarına Göre Etiketler}

RFID etiketler okunma mesafeleri, güç ihtiyaçları, bilgi gönderim kapasitesine göre farklı frekanslarda çalışabilirler. Çalışma frekansı RF sinyallerinin hangi materyalden yayılacağını belirler. Uygulamada metaller ve sıvılar büyük problem oluşturmaktadır. RFID etiketlerde yüksek frekansın kullanılması düşük frekansa göre daha hızlı veri iletimi ve daha uzun mesafelerden iletim sağlamaktadır. Sıvı ve metal bulunan ortamlarda, yüksek frekanslı etiketlere göre düşük frekanslı etiketler daha iyi çalışmaktadır. Çünkü etiket ve okuyucu mesafesi kısa olduğundan ortamdan etkilenme oranı düşecektir [28].

\subsubsection{Düşük Frekanslı (Low Freaquency-LF) Etiketler}

$\mathrm{Bu}$ etiketler genellikle $120-140 \mathrm{kHz}$ frekans aralığında çalışır. Genellikle pasif etiketler düşük frekanslarda çalışır. Okunma mesafesi $1 \mathrm{~cm}$ ile 2 metre arasındadır. Metal ve sıvı gibi zorlu ortamlarda yakın mesafeden çalışabilmektedir. Bundan dolayı implant yapılarak evcil hayvan takibinde kullanılmaktadır. LF etiketler genellikle araba immobilizer sistemlerinde de kullanılmaktadır. Anahtarda bulunan LF etiketi, kontağa yaklaştığı anda çalışır. LF etiketlerin veri okunma oranları düşüktür [24].

\subsubsection{Yüksek frekanslı (High Frequency-HF) etiketler}

$\mathrm{Bu}$ etiketler $13.56 \mathrm{MHz}$ frekansında çalışmaktadır. $20 \mathrm{~cm}$ ile 1 metre arasında okunabilirler. Akıllı kartlarda (MIFARE, ISO/IES 1443), kredi kartlarında, nesne etiketlemede, ID kartlarında, havaalanlarında bagaj izlemede, bina giriş kontrollerinde kullanılmaktadır. LF etiketlerine göre daha yüksek oranda veri okunmaktadır fakat LF gibi sıvı ve metal ortamlarda güvenli okunma yapılamamaktadır. HF etiketleri dar bir frekans bandında çalıştığı için yüksek güvenlik gerektiren uygulamalarda kullanılamamaktadır.

\subsubsection{3. Çok Yüksek Frekanslı (Ultra High Frequency-UHF) Etiketler}

Bu etiketler 860-928 MHz frekans aralığında çalışır. Avrupa'da etiketler $868-870 \mathrm{MHz}$ frekans bandında çalışırken, Amerika ve Kanada'da 902-928 MHz ve Türkiye'de 865.6-867.6 MHz frekans bandında çalışmaktadır. $60 \mathrm{~cm}$ ile 12 metre mesafelerinden okunabilir. Nesne izleme, ürün tedarik ve yönetiminde, palet etiketlemede ağırlıklı olarak kullanılmaktadır. HF ve LF etiketlerine göre sıvı veya metal içerikli ortamlarda okunması oldukça zayıftır. Bunu önlemek için bazı materyaller geliştirseler de verim alınamamıştır [24]. 


\subsubsection{Süper Yüksek Frekanslı (Super High Frequency-SHF) Etiketler}

Bu etiketler $2.45 \mathrm{GHz}$ ya da $5.8 \mathrm{GHz}$ frekanslarında çalışır. Mikro dalga frekanslı etiketler, etiketler olarak da bilinir. 30 metreye kadar okunma yapılabilmektedir. Bu teknoloji son zamanlarda hizla gelişmektedir. Ağırlıklı olarak yarı-pasif ve aktif etiketlerde kullanılmakla birlikte pasif etiketlerde de kullanım imkânı vardır. Yarı pasif mikrodalga etiketleri genellikle filo tanımlamalarında ve ücretli geçiş sistemlerinde kullanılmaktadır. Okunma oranları UHF etiketlere göre daha yüksek olmasına rağmen maliyetleri pahalıdır. Ayrıca düşük frekanslı etiketlere göre daha fazla enerji harcamaktadırlar. Diğer önemli problem ise $802.11 \mathrm{~b} / \mathrm{g}$ wi-fi ağıyla karışma durumudur.

\subsubsection{Ultra Geniş Bant Frekanslı (Ultra Wide Band Frequency-UWB) Etiketler}

$\mathrm{Bu}$ etiketler 3.1-10.6 GHz frekans aralığında çalışmaktadır. Oldukça yeni bir etiket teknolojisidir. Belirli frekanstan oldukça güçlü bir sinyal göndermektense UWB ile geniş bir bant üzerinden düşük güçte sinyal gönderilebilmektedir. Ayrıca sinyalin iletimi daha sağlıklıdır. 200 metrelere kadar okunma yapılabilmektedir. Metal ve sıvı ortamlardan etkilenmez. Hassas okumalarda çevre koşullarından etkilenmez. Bu yüzden sağlık sektöründe, hastane uygulamalarında tercih edilebilir [24].

\subsection{RFID Antenler}

RFID antenler, elektromanyetik dalgaları bir sistemden alıp çevreye veren ya da çevresindeki elektromanyetik dalgalardan aldığı işaretlerle bir sistemi besleyen ve böylece kablosuz haberleşme sistemlerinin performanslarını artırmak için kullanılan bileşenlerdir.

Okuyucu-okuyucu veya okuyucu-etiket arasında haberleşmeyi sağlar. Birçok durumda etiket okuma menzilleri çok düşük olduğu için anten kullanımı çok önemlidir. Konsept olarak basit olmasına rağmen, antenlerin düşük güçlerde en iyi sinyal alımlarını gerçekleştirmeleri ve özel koşullara uyum sağlamaları gerekir. Antenler uygulamaların çalışacağı ortamın özelliklerine ve uygulamanın gerektirdiği mesafelere bağlı olarak, en iyi performansı sağlamak için farklı boy, şekil ve frekans aralıklarında tasarlanmalıdır [29-31].

Antenler, düzlem yayın yapan ve dairesel yayın yapan anten olmak üzere iki çeşittir. Düzlem yayın yapan anten, olası en uzun okuma mesafesinde, maksimum kazanç için tek bir eksende yoğunlaşır. Dairesel yayın yapan anten ise üretilen UHF enerjiyi daha uzun mesafelere eşit bir şekilde dağıtır. Böylece dairesel yönlü yayılım ile o çevrede bulunan bütün etiketlerin okunması sağlanır [32], [33].

Antenlerin bu spesifik özellikleri anten seçimi konusunda önemli olduğu için bu anlamda farklı tasarımlar mevcuttur [34]. Anten seçimi ve tasarımında, okumanın uygun bir şekilde gerçekleşmesini sağlayacak, eksenel oran (AR), 1şıma huzmesinin ön-arka oranı (Front-to-Back Ratio), kenar kulakçık seviyeleri (SLL), yönlendirme ve kazanç ön plana çıkan tasarım parametreleridir. Genellikle RFID uygulamalarında, dairesel polarizasyona sahip anten elemanlar kullanılır. Bu tercihin temel sebebi, herhangi bir doğrultuda yerleştirilmiş etiket ile okuyucu arasındaki haberleşmenin güvenirliliğini sağlamaktır [34].

Ayrıca bir okuyucuya birden fazla anten bağlanabilir. Şekil 7'de anten örnekleri görülmektedir. 

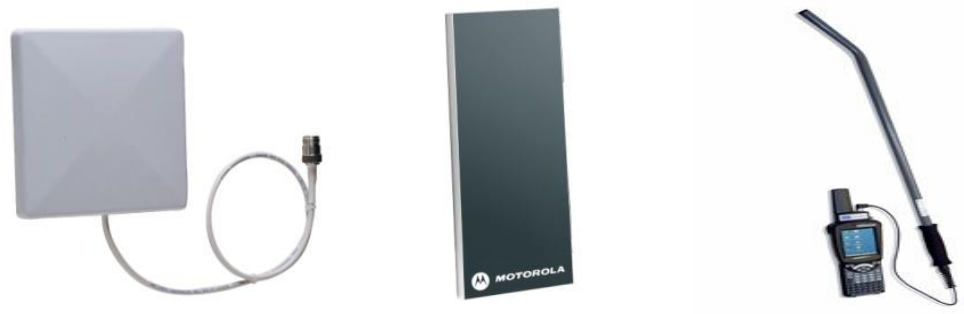

Şekil 7. RFID Antenler [35]

\subsection{RFID Okuyucular}

Mikro denetleyici tabanlı olup anten, tepe dedektörü (etiket tespiti için) ve karşılaştırıcılarla tasarlanmıştır. Sahip oldukları anteni kullanarak radyo frekansı aracığıyla sinyal yayabilen ve geri dönen sinyali (Backscatter - Geri Saçılım) kullanarak etiketle enerji ve bilgi alışverişinde bulunan sistemlerdir. Bazı etiketler enerjisini, okuyucunun gönderdiği sinyallerden antenleri aracılığıyla alırlar. Etiket bu enerjiyi kendi mikroçipini harekete geçirmek için kullanır. Bu enerji ile etiket, antende direnci yükseltip düşürerek bilgiyi okuyucuya gönderir. Okuyucular günümüzde $125 \mathrm{kHz}-2.4 \mathrm{GHz}$ frekans aralığında LF, HF, UHF ve SHF ve UWB frekans bantlarında çalışır. Şekil 8'de RFID okuyucu içyapısı görülmektedir.

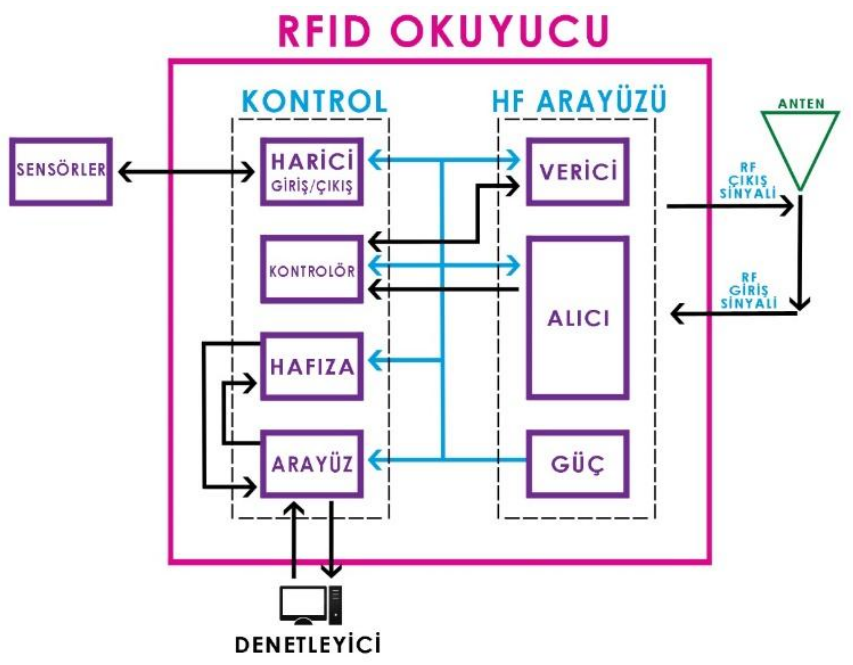

Şekil 8. RFID okuyucu içyapısı [22]

Şekil 9'da genel olarak kullanılan sabit ve mobil RFID okuyucu örnekleri görülmektedir.
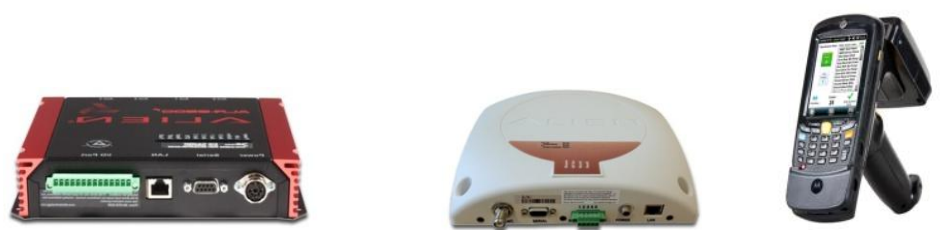

Şekil 9. RFID okuyucular [36] [37] 


\subsection{Denetleyici}

Denetleyici, üzerinde veritabanı yazılımı ya da uygulama yazılımı çalışan bir bilgisayar ya da sunucudur. Denetleyiciler, RFID sistemlerinin beyinleridir ve ara katman yazılımını kontrol ederler. Çoklu okuyucuları ağ ortamında birbirine bağlamak, merkezi olarak bilgileri işlemek için kullanılır. Denetleyici, okuyucular tarafindan toplanan bir alandaki bilgileri kullanır.

RFID sisteminde denetleyicinin yeri Şekil 10'da gösterilmiştir.
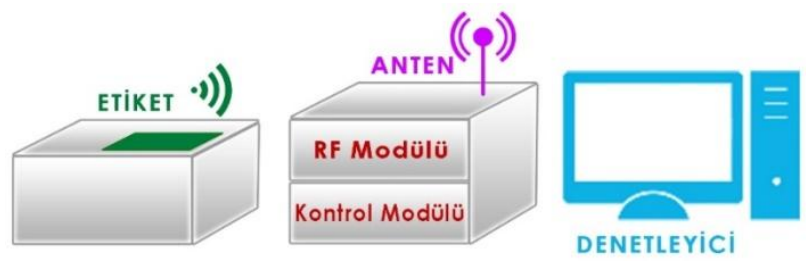

Şekil 10. RFID sisteminde denetleyici [21]

\subsection{Ara Katman Yazılımı (Middleware)}

Bir etiket, nesne üzerindeki işlemler zinciri içerisinde farklı noktalarda aynı ya da farklı okuyucular tarafından birçok defa okunabilir. Bu şekilde her bir okuma okuyucu tarafında ve dolayısıyla RFID sistem ağında etiket verisi üretir. Sonuç olarak, etiketlerin okunması neticesinde RFID sistem ağında çok büyük miktarda veri üretilir. Bu verinin büyük bir kısmı sıkıştırılmış olabilir. Çünkü bunlar aynı ya da farklı çoklu okumalardan oluşabilir. Diğer okumalar ile birleştirilmiş okumalar, firma/kurum mantığı açısından önemli olmayan okumalar, vs. olabilir. Eğer bu veriler olduğu gibi depolanmış ve taşınmışsa, çoğu depolama sistemi ve ağ çökme durumuyla karşılaşabilecektir. Bu verileri verimli bir şekilde tutmak ve gerçek zamanlı olarak yönetebilmek için verilerin sıralanması, filtrelenmesi ve işlenmesi gereklidir. İşte bu noktada, ara katman yazılımı devreye girer. Ara katman yazılımı, RFID sisteminin, RFID sistem ağındaki hizmetlerin, RFID sistemleri arasında dolaşan ilgili bilgi hareketinin ve RFID bilgi sistemleri arasındaki iletişimin yönetilmesinden sorumlu bir yazılım teknolojisidir. Ara katman yazılımı sayesinde veri etkili ve faydalı kullanılır, veri hacmi küçültülür ve veri ağ içerisinde seçilerek iletilir [21].

Savant, WinRFID, WebSphere, Sun Java ve FlexRFID gibi ara katman yazılımları bulunmaktadır. Ara katman yazılımının bileşenleri Şekil 11'de gösterilmiştir.

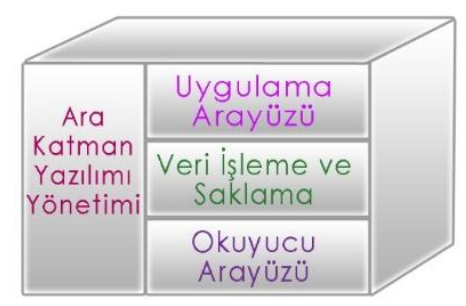

Şekil 11. Ara katman yazılımı bileşenleri 


\subsubsection{Okuyucu Ara Yüzü}

RFID donanım ile etkileşim sağlayan, RFID ara katman yazılımın en alt katmanıdır. Sistemin desteklediği tüm aygıtların sürücülerini içerir ve kablosuz yayın, ana bilgisayar tarafıyla iletişim ve okuyucu protokolleri gibi donanımla ilişkili tüm parametrelerin yönetiminden sorumludur.

\subsubsection{Veri İşleme ve Saklama}

$\mathrm{Bu}$ katman okuyucudan gelen ham verileri işleme ve saklamadan sorumludur. Bu katman tarafindan taşınan mantık işleme örnekleri; veri filtreleme, toplama ve dönüşümdür. Bu katman aynı zamanda kullanılan uygulamaya ilişkin veri seviyesi olaylarını işler.

\subsubsection{Uygulama Ara Yüzü}

RFID ara katman yazılımını konfigüre etmek, iletişim kurmak ve erişmek için bir API(Application Programming Interface - Uygulama Program Arayüzü)'ye ihtiyaç vardır. Bu katman, düşük seviye ara katman yazılımı komutları ile uygulama isteklerini çevirerek, RFID ara katman yazılımı ile kurumsal uygulamaları entegre eder.

\subsubsection{Ara Katman Yazılımı Yönetimi}

RFID ara katman yazılımının konfigüre yönetiminde yardımcı olur ve şu imkânları sağlar.

- RFID okuyuculara bağlantı ekler, konfigüre eder ve değiştirir.

- Filtereler gibi uygulama seviyesi parametrelerini değiştirir ve zamanlama penceresini temizleme işini yineler.

- RFID ara katman yazılımı tarafından desteklenen hizmetleri ekler ve siler [38].

\subsubsection{EPC}

Elektronik Ürün Kodu, her bir nesneyi tek tek tanımlayabilmek için üretilmiş yeni bir nesne tanımlama standardıdır. Firmaların barkodlar için var olan yerleşik standartlarından RFID’ye geçişi için bir yol belirlemek amacıyla, temel küresel ticari ürün numarası yapısı "EPC" benimsenmiştir.

EPC etiketler son kullanıcılar için oldukça farklı alanlarda kullanılabilmektedirler. Bu etiketler bir mağazada ödemesi yapılmayan ürünün dışarı çıkması halinde, mağaza sahibine haber vermede kullanılabileceği gibi bir çamaşır makinesinin içinde ne tür çamaşırlar olduğunu öğrenmede de kullanılabilir [39].

EPC'nin bellek kapasitesi, nesne üreticileri, nesne kategorisi ve nesneye ait bilgiler olmak üzere 3'e ayrılmıştır. EPC kodu; bir önek (header-8 bit), EPC Yönetici Numarası (Manager Number28 bit), Nesne Sinıfi (Object Class-24 bit) ve Seri Numarası (Serial Number-36 bit) olmak üzere 3 dizi veriden oluşan, 64-bit, 96-bit, 128-bit ve 256-bit gibi farkl1 boyutlara sahip bir standart koddur. Önek EPC'nin sürüm numarasını, numaranın ikinci kısmı EPC Yöneticisini (büyük ihtimalle EPC'nin üzerine iliştirildiği ürünün üreticisini), Nesne Sınıfı adı verilen üçüncü kısım ise nesnenin cinsini belirtir. Örneğin, 'Diyet Gazoz $330 \mathrm{ml}$ kutu, Türk sürümü'. Son bölüm ise, ürüne özgün olan ve bize hangi 330 ml'lik Diyet Gazoz kutusundan bahsedildiğini belirten seri numarasıdır. Bu şekilde, 
örneğin, son kullanma tarihleri yaklaşmakta olan ürünlerin kolaylıkla bulunması sağlanabilir. Günümüzde tedarik zinciri uygulamalarında en çok kullan elektronik ürün kodu 96-bit EPC'dir [40], [41]. Örnek bir EPC kod içeriği Şekil 12'de gösterilmiştir.

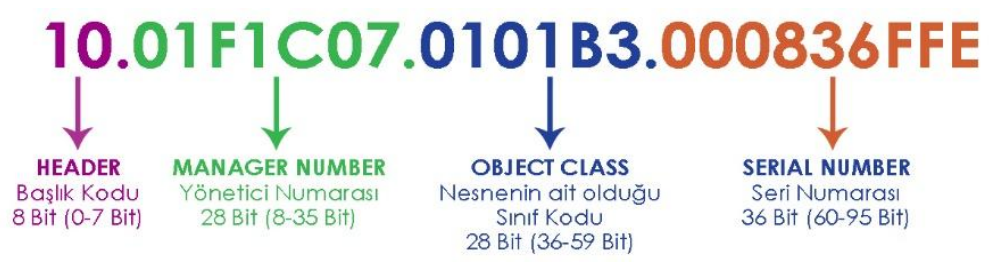

Şekil 12. 96 Bitlik bir EPC içeriği

\subsubsection{EPC Bilgi Hizmetleri}

EPCIS (EPC Information Service - EPC Bilgi Hizmetleri ), kullanıcıların ticari ortaklarla EPCglobal Ağı üzerinden EPC ile ilgili veri takası yapmalarını sağlar.

EPCIS, Güvenlik ve Keşif gibi çekirdek servisler dizisini de tanımlar.

\subsubsection{EPC Keşif Hizmetleri ve Adlandırma Servisi (DS, ONS)}

DS (Discovery Service-Keşif Hizmetleri), kullanıcıların belirli bir EPC ile ilgili veri bulmalarını ve bu veriye erişim izni istemelerini sağlayan bir hizmet paketidir. Keşif hizmetlerinin bir parçası olan ONS (Object Naming Service-Nesne Adlandırma Servisi) ise ürün hakkındaki verinin sağlandığı ilgili EPCIS sunucuları bulmak için kullanılan genel bir hizmettir.

\subsection{EPCglobal Ve RFID A ̆ğ}

EPCglobal, bir ürünün küresel olarak, tüm tedarik zinciri boyunca anında otomatik tanımlama ve takibi sağlamak için RFID teknolojisini, var olan iletişim ağı altyapısını ve EPC'yi birleştiren, tedarik zincirinin gelişmiş etkinlik ve görünürlügünü sağlayan; RFID sistemleri için küresel standartlar geliştirmeye odaklanmış yeni bir küresel ağ sistemidir. EPCGlobal, EPC teknolojisinin standartlaştırılmasını ve dünya çapında benimsenmesini sağlamak amacıyla endüstri liderleri ve akademik kuruluşlardan oluşan üyelik tabanlı bir kuruluştur. EPCglobal'in amacı, tedarik zinciri boyunca nesne görünürlüğünü, etkinliğini, yönetilebilirliğini artırmak ve firmalarla ticari ortakları arasında yüksek kaliteli bilgi akışı sağlamaktır [31,41,42].

EPCglobal'ın Türkiye temsilcisi TOBB bünyesindeki GS1 Türkiye'dir [43].

\section{RFID Sisteminin Çalıșma Prensibi}

Etiket-Okuyucu Bağlantısı: Etiket ile okuyucu girişlerine aynı frekansta bir işareti alacak şekilde bir rezonans devresi eklenir ve böylelikle başka frekanslardan gelen istenmeyen işaretler bastırılmış olur. Etiket aktif ise okuyucudan gelen bu işaret sadece etiketin uyandırılmasını sağlarken etiketin yarı aktif 
veya pasif olması durumunda ise üretilecek cevabın geri-saçılım yöntemiyle gönderilmesinde işe yarayacaktır [12].

Veri Kodlama: Okuyucu ile etiket arasındaki iletişim gerçekleştirilirken verinin de bir kodlama yapılarak gönderilmesi verinin iletim kanalına tam olarak uyum sağlamasını sağlayacaktır. Bu şekilde verinin enterferans (iletilmek istenen bilginin dışında fazlalık bilgilerin de ulaşması) ve başka etiketlerin işaretleriyle çarpışma gibi olgulardan sıyrılması da sağlanacaktır.

Veri kodlama yapılırken gözetilmesi gereken kriterler, kodlanan işaretin etikete taşıyabildiği güç miktarı, sahip olduğu band genişliği ve diğer etiketlerin yol açtığı çarpışma olayına olan bağışıklığı olarak özetlenebilir [44].

$\mathrm{Bu}$ kriterler yakından incelendiğinde, ilki için etikete taşınan gücün maksimum olması istendiği söylenebilir. İkinci kriter için ise kodlanmış işaretin az bir bant genişliği kullanması istenmektedir ki bu sayede pek çok farklı işaret RFID uygulamasına ayrılmış sınırlı frekans bandında kendine yer bulabilsin. Son kriterde ise çarpışmaya olan bağışıklığın yüksek olması istenmektedir ki çok etiketin bulunduğu ortamlarda rahat çalışılabilinsin. Aslında 2. ve 3. kriterlerin çok sayıda etiketin bulunduğu ortamlar için geçerli olduğu söylenebilir [44].

Modülasyon: İletim ortamı olan hava yoluyla verimli veri transferi sağlamanın ikinci önemli yöntemi de gönderilen veriyi modüle ederek göndermektir. Okuyucudan etikete giden işaret, etiketin pasif olması durumunda etiketten okuyucuya geri dönen işaretten çok daha güçlü olacağından bu işareti bastırmas1 ihtimali vardır. Bu ihtimali önlemek amacıyla etiketten okuyucuya geri döndürülecek işaretin genelde gelen taşıyıcı dalganın frekansının bir oranı olan farklı bir taşıyıcı dalga frekansında döndürülmesi sağlanır. Bunu sağlamak amacıyla etikette bir frekans bölücü devresi kullanılır. Geri dönen dalganın taşıyıcısına alt-taşıyıcı adı verilir [45].

Çarpışma: RFID sistemlerinin tasarımında karşılaşılan önemli bir problem de okuyucunun menzilinde olmasına rağmen etiketin okunamamasıdır. Bu tip bir problemle genelde çok sayıda etiketin bulunduğu ortamlarda karşılaşılır. Bu sorunun kaynağı, genelde etiketlerin aynı anda gönderdikleri verilerin birbiri ile karışması veya veri kaybına yol açmasıdır. Bu tip bir durumda etiketin sağlıklı bir şekilde okunabilmesinden bahsedilememektedir. Başka türde etkenler de "çarpışma" denilen olgunun ortaya çıkmasına yol açabilir. Üç tür çarpışma olayı betimlenebilir:

- Tek okuyucu ve çok sayıda etiketin bulunduğu ortamda oluşan çarpışma

- Tek etiket ve çok sayıda okuyucunun bulunduğu ortamda oluşan çarpışma

- İki veya daha fazla sayıda okuyucunun aynı frekans aralığını kullanmaları neticesinde ortaya çıkan çarpışma olayı

Gelişen uygulamalar ile birlikte RFID sistemlerinde çok sayıda etiketin aynı ortamı paylaştı̆̆ 1 uygulamalar yaygınlaşmaktadır. Bunlara örnek olarak, kütüphanecilik, havaalanı bagaj sistemi veya marketlerde ürünlerin kodlanması gibi uygulamalar verilebilir [46].

İşte bu tip uygulamalarda okuyucular, bir ortamda çok sayıda etiketin varlığını algılayabilecek şekilde tasarlanmalıdırlar. Eğer bu algılama yapılamazsa okuyucu aynı anada birden çok sayıda etiketin verisini almaya çalışacaktır ki bu durumun da çarpışmaya yol açacağı açıktır.

$\mathrm{Bu}$ çarpışmanın önüne geçilebilmesi için etiket ile okuyucu arasındaki iletişim için belli bazı kuralların belirlenmesi gerekmektedir. Bu kuralların tümüne "Çarpışma Önleme Protokolü” denir [46]. Pasif etiketlerin sahip olduğu hesaplama yeteneği genelde düşük olduğundan ve birbirleriyle iletişim de kuramadıkları için pasif etiketleri içeren uygulamalarda çarpışmayı önleme meselesi ile okuyucu doğrudan sorumlu olacaktır. Genelde okuyucunun bu sorunu çözme yöntemi olarak belirlenen süreçte önce ortamda menzile giren tüm etiketlerin belirlenmesi, daha sonra da bu etiketlerin tek tek 
tanımlanması gerekmektedir. Tek bir etiketi diğerlerinden tecrit ederek adresleme ve bu yolla tanımlama tekniğine "Tekilleme" denilmektedir. Tekilleme tekniği uygulayarak ortamda bulunan tüm etiketleri tanımlayan okuyucu daha sonraki aşamada istediği etikete bir tek onun adresini ya da tanımlama numarasını kullanarak ulaşabilir ve istediği veriyi çarpışma riski olmadan ondan alabilmektedir. Okuyucu ile etiket arasındaki haberleşmede kullanılan çarpışma önleme protokolleri kullanılan frekansa ve uygulamaya göre standart hale getirilmeye çalışılmaktadır [45].

\subsection{RFID Okuma Mesafesini Etkileyen Faktörler}

Anten kazancı: Okuma aralığı uzaklaştıkça daha yüksek kazançlı antenler kullanılması gerekir. Yüksek kazançlı anten okuyucudan güç alımını artırır. Kazanç birimi olarak dBi, dBic veya dBiL birimleri kullanılır. Bir antenin kazancı 1-15 dBi/dBic/dBiL arasında değişmektedir. Doğrusal antenler doğru konumlandırılıp tek yönlü okuma yaparsa, dairesel antenlere göre daha fazla kazanç sağlar [47]. Anten polarizasyonu: Eğer etiketler antenin polarizasyonuna göre hizalanmışsa, doğrusal polarizasyonlu antenler dairesel polarizasyonlu antenlere göre daha uzağı okuyacaktır. Ya da tam tersi etiket ile antenin görüş açısı uygun değilse dairesel polarizasyonlu antenler daha işlevsel olacaktır. Dairesel antenlerde sadece sol bölge ya da çift yönlü bölge çalışma özellikleri vardır [47].

Etiket boyutu/yönlendirmesi/açısı/yerleştirilmesi: Pasif RFID etiketler, $3 \mathrm{~cm}$ 'den $1.5 \mathrm{~m}$ mesafeye kadar okunabilir. Bu mesafeyi artırmak için büyük kazançlı büyük yapıda antenlere ihtiyaç olacağı için etiketin boyutu büyümelidir. Kullanılan anten polarizasyonuna göre etiketin açısı ve yönlendirmesi ona göre yapılmalıdır. Dairesel polarizasyonlu antenlerde açı ve yönlendirme pek sorun olmazken, doğrusal antenlerde açıyı tutturmak için yönlendirmeyi doğru yapmak gerekir. Antenin metal, su vb. çevresel etkenlerden etkilenebileceğini düşünerek ona göre yerleştirme yapılmalıdır [47].

Okuyucu ayarları: Güç ayarlarının yüksek olması okumanın daha güçlü yapılacağını gösterir. Okuma aralığını maksimize etmek için okuyucunun daha yüksek alım yapacak şekilde duyarlılığı ona göre ayarlanmalıdır [47].

Kablo uzunluğu, çoklayıcılar ve adaptörler: Uzun kablo daha fazla kayıp demektir. Bunun için de çoklayıcılar ve adaptörler kullanmak gerekir. Bu yüzden okuyucudan antene daha kısa kablolar kullanmak gerekir [47].

Çevresel faktörler: Birçok çevresel faktör okuma mesafesini etkiler. Sistemi oluştururken defalarca test ederek farklı varyasyonları hesaba katmak gerekir. Su, metal, florasan ışığı, büyük makinalar, diğer radyo dalgaları UHF RFID okuma aralığını etkileyebilir [47].

\section{RFID Standartlar}

RFID için ISO organizasyonuna ait bazı standartlar ve EPCglobal standardizasyonuna ait olan EPCglobal UHF Class1 Generation2 standartlar1 mevcuttur. Bunların haricinde ASTM(American Society for Testing and Materials) [48], International ve DASH7 [49] standardizasyonlar1 da kullanılmaktadır [50]. 


\subsection{ISO standartlar}

RFID alanında birçok ISO Standardı mevcuttur. Bunlara birkaç örnek verecek olursak;

- ISO 14223: RF ile hayvan tanımlama için

- ISO/IEC 14443: HF standardında yakın mesafeden okuma yapan RFID okuyucu/etiketler için

- ISO/IEC 15693: HF standardında akı1lı ödeme, kredi kartları için

- ISO/IEC 18000: Bilgi Teknolojisi - Nesne yönetimi için RFID [50]

\subsection{EPCglobal UHF Class 1 Generation 2}

EPCglobal GS1 ve GS1 ABD’nin ortak girişimi ile oluşturulmuştur. Diğer ülkelerde dâhil olmuştur. GS1 Türkiye olarak sorumlusu TOBB'dur. EPCglobal Class1 Gen2 standardı 2004 y1lında ISO 18000 serisinin bir parçası olarak geliştirilmeye başlandı. 2006 yılında yapılan küçük değişikliklerle ISO 18000-6 (A-B-C sınıfları) olarak kabul edildi. Gen2 standardı Gen1 standardına göre birçok aşamada gelişme kat etmiştir. Daha hızlı ve daha esnek okuma ve yazma, yüksek güvenirlilik, birçok okuyucu ile erişim ve gelişmiş güvenlik gibi avantajları bulunmaktadır [51].

Son olarak Standart Geliştirme Takımı GSMP (Global Standarts Management Process) üzerinde geliştirmeler yapmaktadır. Hala bazı çalışma grupları GSMP Version1.5 üzerinde çalışmaktadır [51].

- EPC Class 0 Gen 1: UHF sadece okunabilen pasif etiketlerdir. Önceden programlanırlar.

- EPC Class 1 Gen 1: UHF veya HF olarak çalışabilen, bir kere yazılıp çok kez okunabilen(WORM) etiketlerdir [52], [53].

- EPC Class 1 Gen 2 (ID Etiketler): Pasif Geri Saçıllım etiketleridir. Bir EPC ID, bir etiket ID'ye sahiptirler [54], [53].

- EPC Class 2 Gen 2 (Daha Yüksek İşlevsellikte Etiketler): Tedarik zincirinin herhangi bir noktasinda yazılabilen okunur-yazılır pasif etiketlerdir [54].

- EPC Class 3 Gen 2 (Batarya Destekli Pasif Etiketler-Yarı Pasif): Bir güç kaynağı ile etiketler veya sensörler için güç desteği ve sıcaklık, hareket, basınç gibi değerleri kayıt eden sensörler barındırabilir. Yarı-Pasif veya aktif olarak çalışabilirler [54].

- EPC Class 4 Gen 2 (Aktif Etiketler) : Üzerinde verici bulunduran aktif etiketler diğer etiketler ve okuyucularla iletişime geçebilirler [54].

- EPC Class 5 Gen 2: Class 4 etiketlere benzerdiler. Ekstra olarak, başka etiketlere enerji sağlar ve okuyuculardan başka aygitlarla da iletişime geçebilirler [54].

\section{RFID Güvenlik ve Gizlilik}

Auto-ID sistemleri içinde sunduğu birçok avantajdan dolayı ön plana çıkan RFID teknolojisi, farklı noktalarda saldırılara maruz kalmaktadır [55]. Kablosuz sistemlerdeki en büyük tehditlerden birisi verinin güvenliği ve gizliliğidir. RFID sistemlerde ağırlıklı olarak kişisel ve nesneye ait bilgiler taşındığı için bu bilgiler bazı tehditlere maruz kalabilir. Bu tehditler aşağıda listelenmiştir.

- İzinsiz okuma (unauthorise dreading)

- Veri tahrifi (data tampering)

- Etiketin taklidi (tag spoofing)

- Etiketlerin çalışamaz duruma getirilmesi(deactivation of tags)

- Etiketlerin objelerden sökülmesi (removal of tags) 
- Etiket ve okuyucu arasındaki frekansın bozulması(jamming)

- Blockertag kullanımı ile okuyucunun bloke edilmesi(blocking)

- Okuyucuyu tanımlayan verilerin taklidi (reader spoofing)

- Etiket ve okuyucu arasındaki iletişimin izinsiz dinlenmesi (eaves dropping)

- İzleme (tracking)

- Yönlendirme saldırıları (relay attacks)

- RFID - kötücül yazılımları (RFID-Malware) [56]

- Virüsler

- Hizmet Durdurma (denial of service)

\subsection{RFID Güvenlik Önlemleri}

- Kimlik doğrulama (authentication)

- Kod saklama (cover-coding)

- Transfer edilen verinin şifrelenmesi (encryption of data in transit)

- Etikette kayitl1 verilerin şifrelenmesi (encryption of datastored on a tag)

- Kalkanlama (electromagnetic shielding)

- Press-to-activate anahtarının kullanımı

- "Kill” komutu kullanımı

- Kırılır etiketler (clipped tags) kullanımı

- Blockertag kullanımı

- Aktif sinyal bozma yaklaşımı (active jamming)

- "Lock" komutu kullanımı

- Arka uçtaki veri bankasında (backend database) veri saklama

- Takma ad (pseudonym) kullanımı

- Dedektör kullanımı

- Frekans sekmesi (frequency hopping)

- Tekrar adlandırma yaklaşımı (renaming approach)

- RF sistemi kullanıcısı tarafindan taşınan özel cihazlar

- Nizami önlemler (regulative counter measures) [56]

Veri gizliliğinin temini için bazı nizami önlemler de öngörülebilir. Bu tarz önlemlere önemli bir örnek Garfinkel'in "RFID Bill of Rights" [57] adlı bildirisidir. Bu bildiriye göre RFID etiketli ürünleri satın alan tüketicilerin aşağıdaki haklara sahip olmaları gerekir [58].

- Tüketiciler bir ürünün RFID etiketi olup olmadığını bilmek hakkına sahiptir.

- RFID etiketli ürünü satın alan tüketici etiketin sökülmesini veya etkisiz hale getirilmesini isteme hakkına sahiptir.

- Tüketici RFID etiketli ürünü almamayı tercih etse de ya da "kill" komutunun kullanımı ile etiketi etkisiz hale getirtse de ürün ile ilgili diğer haklarını (örn. ürünü iade etmek gibi) kaybetmemelidir.

- Tüketici aldığı ürünün etiketi üstünde hangi bilgilerin kaydedildiğini bilmek hakkına sahiptir.

- Tüketici RFID etiketinin ne zaman, nerde ve ne için okunduğunu bilmek hakkına sahiptir. 


\subsection{RFID Güvenlik Açıkları}

Yeni nesil pasif RFID (pRFID - bataryasız RFID etiketli) sistemlerde, maliyetin düşürülmesi sebebiyle, ak1llı kartlar gibi gelişmiş bir kriptografi (DES, 3DES, AES, ECC) teknolojisini barındıracak bellek ve enerji mevcut değildir. Fakat bu kriptolama yöntemleri RFID etiketleri üzerinde denenmektedir. $\mathrm{Bu}$ anlamda ECC tabanlı etkin bir RFID kimlik doğrulama şeması üzerine çalışma yapılmıştır [59]. Ayrıca 13.56 MHz pasif RFID etiket üzerinde güç ve EM(elektromanyetik) ataklara karş1 bazı şifreleme ve mikro denetleyici çözümleri denenmiştir [60]. Güvenli bir pRFID sistem tasarımı için, mevcut sistem güvenlik açıkları ihtiyaca yönelik olarak incelenmelidir [61].

\section{RFID Uygulamaları}

RFID sistemlerinin hızlı gelişimi, hayatı kolaylaştıran sistemlere sağladığı imkânları ve maliyeti gibi etkenler RFID uygulamalarının sayısını artırmıştır. Bazı yaygın uygulama alanları vardır. Havaalanı bagaj takibi [62], askeri uygulamalar [63], hızlı paketleme, bilet yönetimi, taşıma ve lojistik yönetimi, güvenlik uygulamaları, atık yönetimi, posta takibi, elektronik eşya izleme (EAS), perakende giyim satış1, hırsızlığa karşı değerli eşya koruması, araçlara kontrollü erişim(hız kontrolü [64], yön kontrolü, araç yıkama, yakıt ikmali, sıcaklık kontrolü, kaza önleme sistemleri, park alanları ve yakıt istasyonları tespiti), akıllı ev sistemleri ev izleme ve yönetimi, araç kilitleme sistemi, aracı hırsızlığa karşı koruma [65], kutulanmış/paketlenmiş yiyecekler, ilaç ve medikal cihazlar, personel takibi, müşteri takibi, demirbaş takibi [66], evrak kayıt ve sahtecilik takibi, hastaneler ve sağlık kurumları, kuyumculuk ve antikacılık, kütüphaneler, otopark sistemleri [66], araç takip sistemleri, otoyol ve köprü ücretli geçiş sistemleri, canlı hayvan takip sistemleri RFID sistemlerinde yapılmış uygulamalara birkaç örnektir [67].

RFID teknolojisini kullanarak akıllı park uygulamaları: Bu çalışmada, merkezi veritabanı sistemi kullanılarak üç otoparkın giriş ve çıkış kontrol bilgileri elde edilmiştir. Otoparklar kentin çeşitli yerlerinde bulunmaktadır. Donanım olarak; RFID okuyucu, RFID etiketler, USB kablosu, oyuncak arabalar, USB portundan bağlanan bariyer ve dizüstü bilgisayar kullanılmıştır. Kullanılan RFID okuyucu Phidget markalı, üzerinde bir USB portu, LED ve 5V çıkışı bulunan; $6.9 \mathrm{cmx} 8.1$ boyutlarında, EM Marrin Protokolü (EM4102) ile çalışan bir karttır. Bu sistem ile bir aracın; şehir içindeki park hareketlerini kontrol etmek, hangi tarihte, hangi saatte, hangi parka giriş-çıkış yaptığını kontrol etmek ve ne kadarlık bir ücret tahakkuk ettiğini takip etmek mümkündür. Aynı zamanda bağlı bulunan otoparklar arasında aracın giriş çıkış saatleri merkezi sistemde kayıtlı tutulduğu için varılan otoparkta güncel bilgiler üzerinden işlem yapılacaktır. Ayrıca otoparkın doluluk bilgisi de sistemin kayıtlı tuttuğu bir veridir ve doluluk durumunda uyarı veren bir bilgi destek mekanizması da mevcuttur [68].

Akıllı trafik denetimi ve yönetimi için RFID ile elektronik plaka uygulaması: Büyük şehirler ve otoyollar için elektronik plaka ile trafik denetimi ve yönetimi yapılabilmesi için geliştirilmiş bir sistemdir [69].

RFID teknolojisi ile e-sınav uygulaması: Yazılım ile okulun e-sınav salonlarının merkezi bir veritabanı çerçevesinde otomatik olarak işletilmesi, kontrol edilmesi ve raporlanması amaçlanmıştır. Donanım olarak kullanılan RFID okuyucu ve etiketler ile de e-sınav salonlarının giriş ve çıkış kontrolü yapılmıştır. Böylece klasik olarak yapılan sınavlara alternatif olarak, çevrimiçi olarak işletilebilen, kontrol edilebilen ve otomatik öğrenci tanıyabilen e-sınav uygulaması gerçekleştirilmiştir [70]. 
Yatarak tedavi gören şizofreni hastalarının negatif belirtilerinin RFID teknolojileri ile ölçülebilirliğinin değerlendirilmesi: RFID uzaktan tanımlama yöntemiyle şizofreni hastalar üzerinde hareketlilik ve ilaç etkilerine dair birçok soruya cevap alınmaya çalışılmıştır [14].

Trafik sinyali kontrol ve yönetimi (ZigBee ve RFID): Özgün algoritmalı RFID/ZigBee trafik kontrol sistemi verimli bir zaman yönetimi şeması ile çoklu yol, çoklu kavşak, çoklu araç için kullanılabilirliğini kanıtlanmıştır [71].

Aktif RFID kullanarak iç mekânda yer algılaması(LANDMARC): GPS sistemi gibi yer tespiti yapan sistemler uydulara bağlı kalmaktadır. Bu projedeki amaç iç mekândaki kablosuz cihazları kullanarak yer tespiti yapmaktır [72].

Radyo frekans kimlik tanıma sistemleri ile elektronik para uygulamasının gerçeklenmesi: RFID teknolojisi kullanılarak hem ürünün okutulduğu, hem kimlik tanıma işleminin, hem de kart üzerinde şifre ile işlemlerin yapıldığ 1 bir "elektronik para" uygulaması yapılmıştır. Bu çalışma için 13,56 MHz de çalışan pasif mifare kartlar ve SMRFID 1013 demo kiti kullanılmıştır. Yazılımı Visual Studio 2005. NET platformunda C\# dilinde geliştirilmiştir. Ürünler ve kişiler için ayrı ayrı kartlar tanımlanarak, ürün kart bilgileri ve kredi kartı için kimlik ve bakiye bilgileri demo kitin SMRFID programı ile işlenmiştir [73].

Hasta Takip Sistemlerinde RFID Uygulaması: Bu çalışmada, RFID iletişimi sağlık sisteminde kullanılmıştır. Önerilen sistem, RFID okuyucusu barındıran bir PDA cihazı ile RFID etiketi barındıran bir bileklik arasında gerçekleştirilen kablosuz iletişim rahatlığı sayesinde, hastaları takip etmede yardımcı olabilir. Bu bildiri RFID iletişim standartlarını inceleyip önerilen RFID tabanlı hasta takip sisteminin tasarımını ve uygulamasını aktarmaktadır [74].

HGS (Hızlı geçiş sistemi): Boğaz Köprüleri ve Otoyol geçişlerinde ödemenin pasif RFID teknolojisi kullanılarak gerçekleştirildiği Türkiye‘de 17 Eylül 2012 tarihinde kullanılmaya başlanan bir ücretlendirme sistemidir. Ücret toplama işlevi gişelerde yer alan antenler aracılığı ile araç üzerindeki etiketin algılanması ve bu etiket ile ilişkilendirilmiş hesaptan tahsil edilmesi esasına dayanır. Böylelikle gişelerde ödeme yapmak için duraksamadan hızlı bir geçiş sağlanır. Sistemde ek olarak gişelerden geçen aracın dört farklı açıdan görüntüsünü çekerek sınıf ve plakasını tespit eden akıllı kameralar kullanılmaktadır. Tüm bu artı özelliklerine rağmen, Hızlı Geçiş Sisteminin yatırım maliyeti, mevcut sisteme göre çok daha düşüktür [75].Otoyol ve köprülerde ilk çıkan OGS ve KGS uygulamalarında bazı aksaklıklar yaşanmıştır. OGS'lerde cihaz maliyetinin yüksek oluşu ve tüm ihtiyaçları karşılamayışı, KGS'lerde köprülerdeki yavaşlamalardan dolayı zaman sarfiyatı ve kart limiti sorunlarından dolayı HGS sistemine geçilmiştir. Şu an itibariyle çok hızlı geçen araçları okumama gibi sorunları olsa da bir önceki sistemlere göre daha işlevsel ve geliştirilebilir olması bu sistemi kullanmayı cazip kılmaktadır.

RFID Teknolojisinin Acil Müdahalede Kullanımı: $\mathrm{Bu}$ çalışmada merkezi bir veritabanı kullanılarak, kazalarda yaralanan kişilere yapılan müdahalelerin neler olduğunu ve aşamalı olarak nerelere nakil edildiklerine dair bilgi bankası oluşturulmuştur. Uygulama genel olarak bilgi toplama katman1, PC katmanı, internet ve veritabanı katmanlarından meydana gelmektedir. Veri toplama katmanında RFID okuyucular, RFID pasif etiketler yer almaktadır. PC katmanında ise mobil bilgisayarlar ve uygulama yazılımları yer almaktadır. İnternet alt yapısı üzerinde erişilecek olan veritabanı yönetim sisteminde ise veritabanı yazılımı ve ülke çapında tüm kaza ve müdahale bilgilerinin erişileceği KAZAZEDE veritabanı yer almaktadır. Uygulamada bir yandan donanım kullanılırken diğer yandan yazılım da kullanılmıştır. Donanım olarak dizüstü bilgisayarlar ve bu 
bilgisayarlara kablolu ya da kablosuz olarak haberleşebilecek mobil RFID okuyucular kullanılmıştır. RFID okuyuculardan alınan yaralı bilgileri önce mobil bilgisayardaki yerel veritabanına ardında internet altyapısı üzerinden KAZAZADE veritabanına aktarılmıştır. Uygulama yazılım için de Microsoft C\# 2008 programlama dili kullanılmıştır. Veritabanı ise Microsoft SQL Server 2005 Express Edition sürümü vasıtasıly idare edilmiştir.

Sistem kaza yerine gidecek olan ambülânsta yer alması gereken mobil bilgisayarlar, uygulama yazılımı ve bilgisayara bağlı olarak kullanılacak RFID mobil okuyucular ve RFID etiketlerin hazırlanması ile çalışmaya başlar. Öncellikle kaza yerinde her bir kazazedeye birer tane RFID etiket bileklerine takılır. $\mathrm{Bu}$ aşamada yaralının cinsiyeti, konuşabiliyorsa adı, soyadı, yaşı, kaza yeri, ilk etapta ve kimler tarafından yapıldığı müdahaleler kaydedilir. Tarih ve saat bilgileri otomatik olarak kaydedilir. Uygulama yazılımı vasitasıyla bu bilgiler RFID okuyucu üzerinden okunup yazılabilen RFID etiketlere kaydedilir. Bundan sonra eğer yaralı ilk yardımın yapılacağı bir sağlık ocağı ya da bir hastaneye kaldırılırsa o zaman burada yapılan işlemler yine RFID okuyucu ile etiketlere bir kez daha yazılır. Son olarak yaralının kaldırılacağı tam teşekküllü hastane bilgileri ve nakil biçimi de kendisine at RFID etikete yazılır.

Tam teşekküllü hastanede yaralıya yapılan müdahaleler ve yaralının gerçek iletişim bilgileri de alınarak kendisine ait etikete kaydedilir. Etiketteki bilgiler okutularak uygulama yazımlı vasitasıyla internet alt yapısı üzerinden erişilecek KAZAZADE veritabanına kaydedilir. KAZAZEDE web sitesi ile bağlantı kurulan veritabanı üzerinde arama yapılarak istenen kişinin hangi hastanede olduğu ve durumunun ne olduğu öğrenilebilir [76].

NFC: NFC (Near Field Communication-Yakın Alan İletişimi), yeni nesil bir kablosuz iletişim teknolojisidir. NFC teknolojisi temelde, NFC standartlarına uyumlu elektronik cihazlar arasında yakın mesafeli haberleşmeyi sağlar. RFID tabanlı olup $13.56 \mathrm{MHz}$ bandında işlev görür. 2002 yılının sonlarında Sony ve Philips ortaklığında geliştirilmiş ve ISO/IEC tarafından 8 Aralık 2003 tarihinde standart olarak kabul edilmiştir. 18 Mart 2004 tarihinde Nokia, Sony ve NXP tarafindan NFC Forum, NFC teknolojisinin geliştirilmesi ve yaygınlaştırılması için kurulmuştur [77]. Günümüzün artan bağlantılı dünyasında, bu basit, sezgisel teknoloji basit bir dokunuşla etrafınızdaki dünya ile güvenli etkileşim sağlar. Hızlı, kesintisiz ve kullanımı kolay, NFC neredeyse her gün gelen akıllı telefonlar, tabletler ve diğer tüketici elektroniği gibi yüz milyonlarca yeni cihazlar ile artık kullanılabilir [78].

Müze Ziyareti Deneyimlerini Artırmak İçin Aktif RFID Teknolojisi Uygulama Önerisi: Aktif RFID tabanlı bir kulaklık kullanılarak kültürel yerler hakkında ziyaretçiye bilgi vermesi amaçlanmıştır. Hatta bu bilgi geleneksel bir rehberin verdiği bilgiden daha fazlası ve daha doğru bilgiler olabilir. Müzedeki değerli eşyaya tanımlanan bilgilerle ziyaretçi istediği dilde eşya hakkında bilgi alabilir. Bu tasarım önerisi, müze ziyaretçilerini ve yükselen kârlarını artırmayı ve büyük ölçüde müze için bakım maliyetlerini azaltmayı hedeflenmektedir [79].

RFID ile Araç Bilgisi Depolama Sistemi: Volkswagen grubunun Uruguaylı ithalatçısı araç bilgisi depolayan bir sistem geliştirmiştir. Şirket; bu sistemdeki amacının, şimdilik kendi ithalat ve satış bilgilerinin yanı sıra tarih, sağlanan tüm bakım dâhil, her aracın yaşam geçmişini kaydetmek için bu teknolojiyi kullanarak bir plan geliştirilmesi olduğunu belirtmektedir [36].

Coca Cola'dan Başarılı Uygulama: Coca-Cola 2010 yazında İsrail'de gençlere yönelik eğlenceler, konserler ve yarışmalar düzenlendiği Coca-Cola Village etkinliğinde dağıttı̆̆ RFID bilekliklerle facebook profilini tanımlayan katılımcıların hangi oyunlara katıldığı ve bu etkinliklerde çekilen fotoğraflarının anında profillerinde görünmesini sağlamıştır. 1500 adet RFID bilekliğin dağıtıldığı kampanyada günlük 652,700 post görüntülenmiştir [80]. 
Mobilya Satışında RFID Uygulaması: John Lewis müşterilere mobilya seçiminde RFID tabanlı farklı bir sistem sunmaktadır. Minyatür boyutlarda RFID etiketli mobilyalar okuyucu tarafindan okutularak mobilya hakkında bilgiler sunmaktadır. Gerçek boyutları, renk seçenekleri, mobilya ile ilgili resimler gibi fabrikasyon haliyle bir izleme ekranında bilgiler sunmaktadır [81].

\section{RFID Sistemlerinin Pazar Durumu ve Tedarik Zinciri}

RFID sistemlerin başta gelen üreticileri; Thing Magic, Alien Technology, Motorola, Venture Research, Arcadian, Kirk-Rudy, SMARTRAC, Zebra Technologies, Fujitsu, Metal Craftfirmalarıdır. Her yıl pazar durumunda yerini sağlamlaştırarak ilerleyen RFID sistemlerin mimarileri, RFID geliştiricilerinin fikirlerinden yola çıkarak daha ucuz daha kullanışlı ve diğer teknolojilerle bütünleşik RFID sistemleri üretme yarışındalar. Her yıl düzenlenen Uluslararası RFID Kongresinde firmalar ürettikleri okuyucu, etiket, anten gibi bileşenleri tanıtma amacındadırlar. Bunun yanında RFID sistemi ile yeni çözümler bulan araştırmacıların projeleri sunulmaktadır.

IDTechEx (2015) raporuna göre toplam RFID Pazar değeri 10.1 milyar dolardır. 2013 y1lında 8.8 milyar dolar, 2014 yılında 9.5 milyar dolar olan pazar değerinde büyük bir artış görülmüştür. Bunun içinde etiketler, okuyucular, yazılımlar vb. diğer bütün maliyetler bulunmaktadır. IDTechEx'in tahminine göre 2020 yılında bu rakam 13.2 milyar doları bulacaktır. 2016 yılında geçiş için kullanılan bilet biçiminde 800 milyon etiket talep edilecektir. UHF pasif etiket satışları HF etiket satışlarının \%11'i kadardır [82]. RFID etiket pazarındaki son 5 yıllık artış muazzam boyutlardadır. Moda üreticilerinin mimarı olan Zara şirketi 2000 mağazasında RFID sistemini kullanarak en büyük paya sahip olmuştur. RFID etiketlere dair pazar oranları ise Çizelge 2'de gösterilmiştir.

Çizelge 2. Pasif RFID etiket kullanım raporları [83]

\begin{tabular}{|l|c|c|l|c|c|}
\hline Pasif UHF(milyon) & \multicolumn{2}{l|}{ Pasif HF(milyon) } \\
\hline Uygulama & $\mathbf{2 0 1 3}$ & $\mathbf{2 0 1 4}$ & Uygulama & $\mathbf{2 0 1 3}$ & $\mathbf{2 0 1 4}$ \\
\hline Perakende giyim ve ayakkabı & 2250 & 3000 & Temassız kartlar ve anahtarlıklar & 1250 & 1400 \\
\hline Diğer perakendeler & 25 & 50 & Akıllı etiketler & 600 & 700 \\
\hline Lojistik-taşıma & 125 & 125 & Kitaplar & 90 & 95 \\
\hline Portföy yönetimi ve envanteri & 450 & 475 & Medikal & 22 & 28 \\
\hline Medikal/sağlık bakımı & 18 & 23 & Portföyler ve araçlar & 105 & 110 \\
\hline Havaalanı bagaj ve kargo takibi & 72 & 74 & Pasaportlar & 75 & 80 \\
\hline Erişim kontrolü ve bilet takibi & 1.5 & 2 & Innsanlar & 5 & 6 \\
\hline Gömülü sistemler & 0.1 & 2 & NFC uygulamaları & 10 & 30 \\
\hline İnsanlar & 22 & 24 & Diğer & 25 & 30 \\
\hline Diğer & 65 & 70 & & & \\
\hline Toplam & $\mathbf{3 0 2 9}$ & $\mathbf{3 8 4 5}$ & Toplam & $\mathbf{2 1 8 2}$ & $\mathbf{2 4 7 9}$ \\
\hline
\end{tabular}

Araştırmalar ve olaylar üzerinde çalışan IDTechEx gelecek 10 yılda RFID kullanımına ilişkin öngörüleri Çizelge 3'de gösterilmiştir [82]. 
Çizelge 3. RFID pazar tahminleri

\begin{tabular}{|l|l|l|}
\multicolumn{1}{|c|}{$\begin{array}{c}\text { Pasif UHF RFID Pazar } \\
\text { Verileri - 10 yıllık tahmin }\end{array}$} & $\begin{array}{c}\text { Pasif HF RFID Pazar } \\
\text { Verileri - 10 yıllık tahmin }\end{array}$ & $\begin{array}{c}\text { Pasif LF RFID Pazar } \\
\text { Verileri - 10 yıllık tahmin }\end{array}$ \\
\hline Perakende giyim ve ayakkabı & Temassız kartlar ve anahtarlıklar & Canlı stok ve evcil hayvanlar \\
\hline Diğer perakendeler & Akıllı etiketler & Erişim kontrolü \\
\hline Lojistik-taşıma & Kitaplar & Araç anahtar tanıma sistemi \\
\hline Portföy yönetimi ve envanteri & Medikal & Medikal \\
\hline Medikal/sağlık bakımı & Portföyler ve araçlar & İnsanlar \\
\hline Havaalanı bagaj ve kargo takibi & Pasaportlar & Diğer \\
\hline Erişim kontrolü ve bilet takibi & İnsanlar & \\
\hline Gömülü sistemler & NFC uygulamaları & \\
\hline İnsanlar & Diğer & \\
\hline Diğer & & \\
\hline
\end{tabular}

RFID çözümlerin oluşturulmasında entegre çalışan çip üreticisinden okuyucu üreticisine kadar bir bütünlük içerisinde her birimin bir tedarikçisi bulunmaktadır. Bu tedarikçiler Şekil 13'de gösterilmiştir.

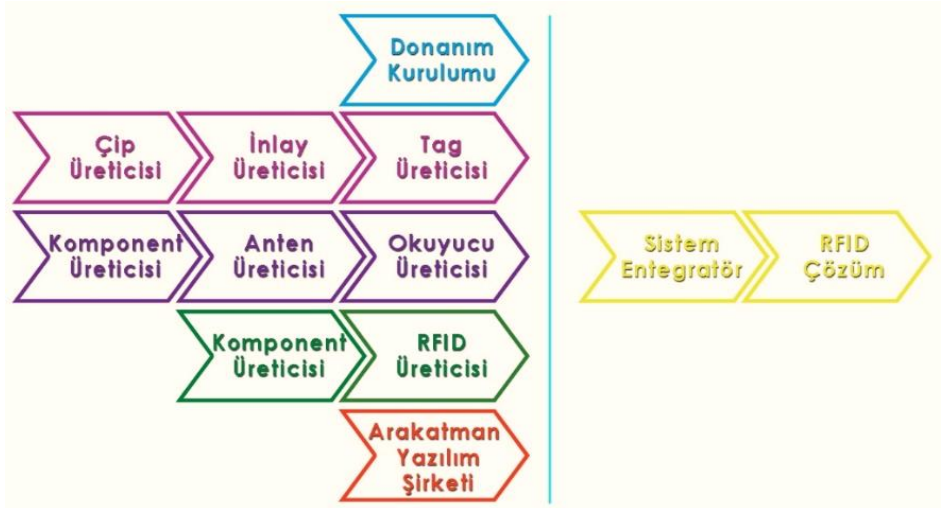

Şekil 13. RFID pazar durumu ve tedarik zinciri [84]

Pazar durumunda bazı engeller bulunmaktadır. Şekil 14’te gösterildiği gibi RFID çözümlerin oluşturulmasında her birimde belli oranda engeller vardır.

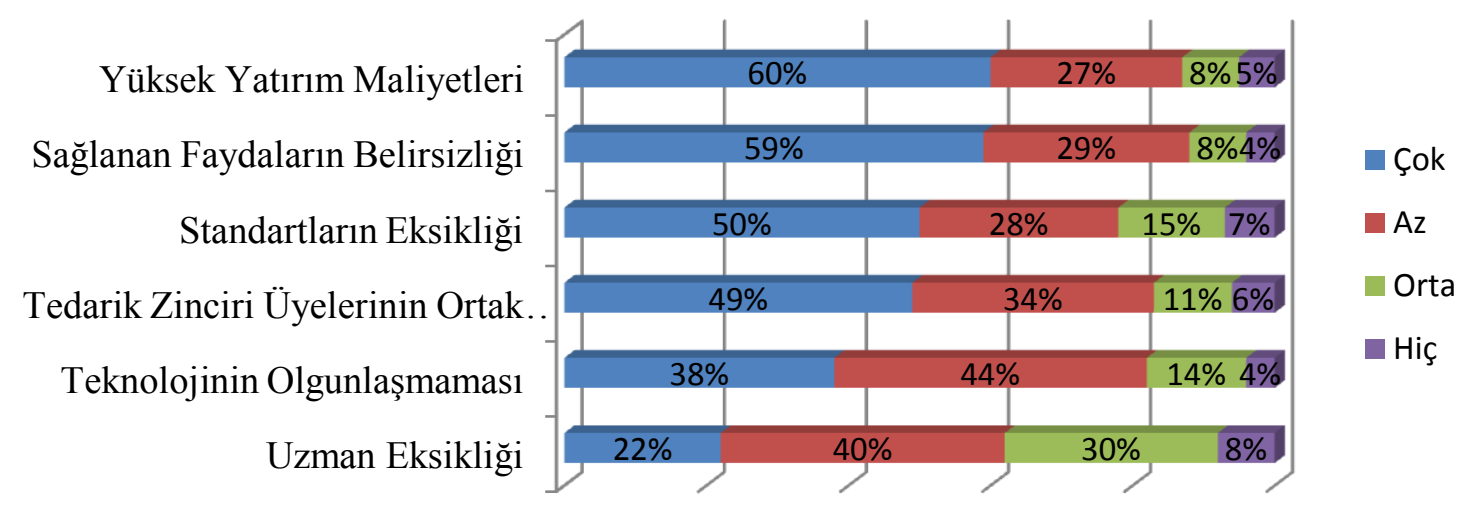

Şekil 14. Yatırım önündeki engeller [84] 
RFID sistemi, senkron çalışan ve verimliliği, güvenirliliği, doğruluğu ortaya çıkaran bir süreçten geçmektedir. Bu süreç Şekil 15’te gösterilmiştir.

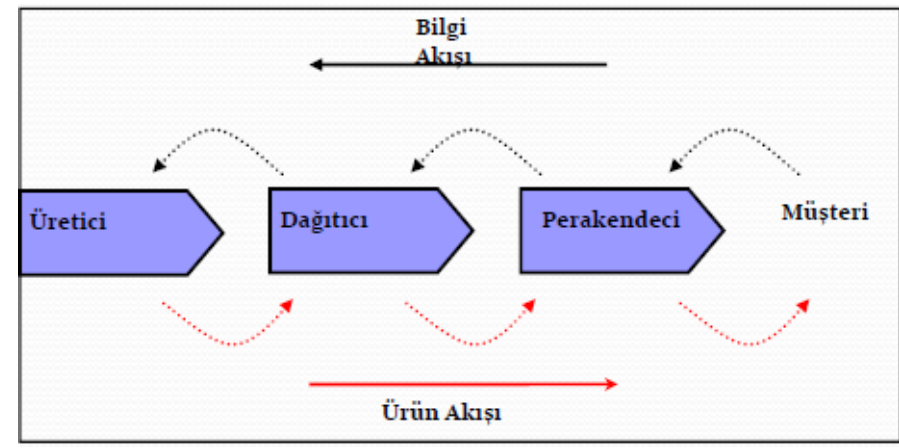

Şekil 15. RFID ürün süreci [84]

\section{Sonuç}

Kablosuz sistemler geliştikçe, birçok soruna çözüm bulunmakta ve kullanım sahası gittikçe artmaktadır. Bu sahada esnek, güvenilir, uygulanabilir ve ucuz maliyetli olan birçok kablosuz sistemle entegre edilebilen RFID sistemlerin payı da büyük olacaktır.

RFID kapasitesinin artırılması konusunda çok geniş çapta bir çalışma yapılmaktadır. Manyetik RAM ya da MRAM [85] denilen sistemler üzerinde çalışmalar devam etmektedir. MRAM, nano boyutlardaki manyetik bit dizileri ile bilgiyi saklar. MRAM'in üzerine yazma, her bir bit'in manyetik kutuplarını değiştirerek yapılıyor olması ve bu değerin elektrik gereksinimi duymadan saklanabiliyor olması demektir. Gelecekteki nano teknoloji uygulamaları, mürekkep tabanlı RFID devrelerini mümkün kılarak silikon çip gereksinimi ortadan kaldırabilecektir. Bunun en iyi örneği tamamen mürekkepten geliştirilen bir prototip olan Organik ID'dir [86] ve maliyeti 0.01 doların altındadır. Organik ID'nin 5-10 yıl arasında yaygınlaşması beklenmektedir [87].

Yapılan araştırmalara göre gün geçtikçe RFID sistemlerin pazardaki konumu ve yükselen grafiği gösteriyor ki bu sistem daha birçok probleme çözüm olacaktır. Bu süreçte geliştiricilerin farklı alanlarda RFID kullanmaya başlaması ve ihtiyaca yönelik olarak sistemin optimize edilmesi, küçük bir sistemle büyük işlerin yapılabileceğini göstermektedir. Fakat yapılan projelerde bilgi akışı fazlalaştıkça güvenlik sorunları ortaya çıkabilmektedir. Bununla ilgili olarak da farklı güvenlik algoritmaları geliştirilmektedir [88].

Sonuç olarak bu çalışmada RFID sistemlerin gelişimi, yapısı ve kullanım alanları irdelenmiştir. RFID ile geliştirilen uygulamalar birçok farklı alanda uygulanabilmekte olup sektörlerde fazlaca kullanılmış olması bu sistem üzerinde farklı projelerin üretilebileceği konusunda bizlere yol gösterici olacaktır.

\section{Kaynaklar}

1. Discover Wi-Fi, 15 Years of Wi-Fi. http://www.wi-fi.org/discover-wi-fi/15-years-of-wi-fi. (Erişim Tarihi: 19.04.2015).

2. Xydis TGP, Blake-Wilson S, 2001. Security Comparison: BluetoothTM Communications vs. 802.11 
3. NFC Forum. NFC and Contactless Technologies. http://nfc-forum.org/what-is-nfc/about-thetechnology/. (Erişim Tarihi: 19.04.2015).

4. Knutson CD, 1997. Infrared Data Communications with IrDA. IrDA Test and Interoperability Committee. Counterpoint Systems Foundary, Oregon.

5. Franklin LP, 2009. ZigBee Overview. ZigBee Alliance.

6. Lord Bowden of Chesterfield, M.A., Ph.D., M.Sc.Tech., D.S., L.L.D., C.Eng.,Fel.I.E.E.E., F.I.C.E., F.I.E.E. 1985. The story of IFF (identification friend or foe). IEE Proceedings. 132: 435437, Washington.

7. Şahin ÖE, 2010. RFID Teknolojisinde İnsan Bilgisayar Etkileşimi. Ajit-e Bilişim Teknolojileri Akademik Dergisi, P. 3.

8. Want R, 2006. An Introduction to RFID Technology. IEEE Pervasive Computing. Intel Research. Santa Clara.

9. Bhuptani M, Moradpour S, 2005. RFID Field Guide: Deploying Radio Frequency Identification Systems. New Jersey: Sun Microsystems Press.

10. Pala Z, 2007. RFID Teknolojisi İle Otomasyon Bir Uygulama Olarak: Otopark Takibi. ElektrikElektronik Mühendisliği Anabilim Dalı, Yüksek Lisans Tezi, 33s.

11. Demirel F, 2007. Tedarik ve Lojistik Yönetiminde RFID Uygulamalar1. p. 44, İTÜ- İstanbul.

12. Finkenzeller K, 2003. RFID Handbook.

13. Stockman H, 1948. Communication by Means of Reflected Power. Proceedings of the I.R.E.

14. Kocamaz AF, 2008. Yatarak Tedavi Gören Şizofreni Hastalarının Negatif Belirtilerinin RFID Teknolojilerle Ölçülebilirliğinin Denetlenmesi. Bilgisayar Mühendisliği Ana Bilim Dalı, Yüksek Lisans Tezi, 115 s. Edirne.

15. Dilonardo RL, 2014. EAS Source Tagging 20-Plus Years of Inoovation. Loss Prevention Magazine.

16. Bazaatı S, 2012. İnşaat Sektöründe Radyo Frekanslı Tanımlama (RFID). Çukurova Üniversitesi Fen Bilimleri Enstitüsü İnşaat Mühendisliği Anabilim Dalı, Yüksek Lisans Tezi, 96s, Adana.

17. AIM Inc. http://rfid.mantis.com.tr/2008/05/rfid/. (Erişim Tarihi: 10.10.2014).

18. Üstündağ A, Tanyaş M, 2009. Radyo Frekanslı Tanıma (RFID) Teknolojisinin Tedarik Zinciri Üzerindeki Etkileri, İTÜ Dergisi, 8 (4): 83-94.

19. Chiesa M, Genz R, Heubler F, Mingo K, Noessel C, Sopieva N, Slocombe D, 2002. RFID Background and Research. Interaction Design Institute Ivrea, p. 03.

20. Atlas RFID Solutions. The Basics of an RFID System. http://rfid.atlasrfidstore.com/hsfs/hub/300870/file-252314647-pdf/Content/basics-of-an-rfid-system-atlasrfidstore.pdf, （Erişim Tarihi: 01.11.2014).

21. Yüksel ME, Zaim AH, 2009. RFID’nin Kablosuz İletişim Teknolojileri İle Etkileşim. Akademik Bilişim, Şanlıurfa.

22. Repanovici A, Cristea L. RFID-Application in Info-Documentary Systems.

23. Shenzhen Meihe Induction Technology Co.Ltd. http://www.mhrfid.com/product/28.aspx?gclid=CJ3i-9C4qL4CFRQbtAodvRAAHQ. (Erişim Tarihi: 14.05.2014).

24. Weis SA, 2011. RFID (Radio Frequency Identification): Principles and Applications.

25. Li M. Vanch VT-3004 semi passive rfid tag uhf. http://www.alibaba.com/product-detail/VanchVT-3004-semi-passive-rfid_1866113106.html?s=p. (Erişim Tarihi: 23.04.2015).

26. Cisco Systems. RFID Tag Considerations. 20.05.2008. Wi-Fi Location-Based Services 4.1 Design Guide, no. OL-11612-01, pp. 6-1, 6-31.

27. Yılmaz H, 2013. RFID Akıllı Etiketler, Uygulama Alanlarının İncelenmesi ve Öneriler. Bilgi Teknolojileri ve İletişim Kurumu, Samsun. 
28. Ergen E, 2008. İnşaat Sektöründe Radyo Frekanslı Tanımlama Teknolojisi Uygulamaları, No: 451.

29. Ranasinghe D, Leong $\mathrm{K}, \mathrm{Ng} \mathrm{M}$, Cole P, 2006. Small UHF RFID label antenna design and limitations.

30. Kraus JD, Marhefka RJ, 2002. 3rd ed.Antennas-For All Applications. New York: McGraw-Hill.

31. Lahiri S, 2006. RFID Sourcebook.

32. Hossain S, Karmakar N, 2006. An Overview On RFID Frequency Regulations And Antennas. Dhaka, Bangladesh.

33. Syed A, Ilyas S, 2008. RFID Handbook, Applications, Technology, Security, and Privacy.

34. Uçar M H, Sondaş A, Erdemli Y E, 2010. Çevrimiçi RF Veri Toplama Sistemi için UHF-RFID Okuyucu Anten Tasarım. V. URSI-Türkiye 2010 Bilimsel Kongresi, Güzelyurt.

35. Boer Bilişim A.Ş. http://www.boer.com.tr/tr/b-80-0-rfid-antenler.asp. (Erişim Tarihi: 14.05.2014)

36. Swedberg C, 2013. Motorola Sled Reader Adds Low-Cost RFID. RFID Journal, p. 2.

37. Alien Technology LLC. http://www.alientechnology.com/readers/smart-antenna/. (Erişim Tarihi: 22.10.2014).

38. El Khaddar MA, Boulmalf M, Harroud H, Elkoutbi M, 2011. RFID Middleware Design and Architecture in Design and Deploying RFID Applications, Edited by Turcu C., InTech., 305-327 Morocco,UAE.

39. Castelluccia C, Soos M, 2007. Secret Shuffling: A Novel Approach to RFID Private Identification. Conference on RFID security 07, Malaga.

40. Finkenzeller K, 2005. RFID Handbook, Wiley Press. New York.

41. Bhatt H, Glover B, 2006. RFID Essentials.

42. Brown D, 2007. RFID Implementation. McGraw Hill Professional. 466s.

43. TOBB-Türkiye Odalar ve Borsalar Birliği, 2012. GS1 Sistemi Tanıtım Kitapçı̆̆ı. http://www.gs1tr.org/yayinlar.php, Ankara.

44. Weis S, 2003. Security and Privacy in Radio-Frequency Identification Devices, Massachusetts: MIT.

45. Bulut K, Örs B, İlker Y, 2008. RFID Sistemlerinin İncelenmesi ve Mikroişlemci üzerinde Güvenli Olacak Şekilde Gerçeklenmesi. 3. Uluslararası Katılımlı Bilgi Güvenliği ve Kriptoloji Konferans1, Ankara.

46. Lehpamer H, 2008. RFID Design Principles.

47. Armstrong S, 2013. 6 Factors that Affect RFID Read Range. http://blog.atlasrfidstore.com/improve-rfid-read-range (Erişim Tarihi: 01.11.2014).

48. ASTM International. Overview. http://www.astm.org/ABOUT/full_overview.html (Erişim Tarihi: 24.04.2015).

49. Andre M. DASH7 Alliance. http://www.dash7-alliance.org/?page_id=28, (Erişim Tarihi: 24.04.2015).

50. Vikipedi. Radio-frequency identification, 2014. http://en.wikipedia.org/wiki/Radiofrequency_identification, (Erişim Tarihi: 25.10.2014).

51. GS1. http://www.gs1.org/epcglobal/standards, (Erişim Tarihi: 21.05.2014).

52. Barber G, Tsibertzopolous E, 2005. An analysis of using EPCglobal class-1 generation-2 RFID technology for wireless asset management.

53. Jaemin P, Junchae N, Minjeong K, 2007. A Practical Approach for Enhancing Security of EPCglobal RFID Gen2 Tag.

54. Tag Classification Definitions. http://www.gs1.org/docs/epcglobal/TagClassDefinitions_1_0whitepaper-20071101.pdf, (Erişim Tarihi: 22.05.2014).

55. Pala Z, 2008. RFID Teknolojisi ve Güvenlik Tehditleri, Ağ ve Bilgi Güvenliği Sempozyumu, p. 136, Girne. 
56. Bayrak Meydanoğlu E S, 2008. RFID Sistemleri ve Veri Güvenligi. Bilişim Teknolojileri Dergisi, 1 (3).

57. Garfinkel S, 2002. An RFID Bill of Rights. MIT. http://www.technologyreview.com/article/401660/an-rfid-bill-of-rights/. (Erişim Tarihi: 24.04.2015).

58. Korkmaz E, Üstündağ A, Tanyas M, 2006. Standards, Security \& Privacy Issues about Radio Frequency Identification (RFID), İzmir.

59. Chou JS, Chen Y, Wu CL, Lin CF, 2011. An efficient RFID mutual authentication scheme based on ECC.

60. Hutter M, Mangard S, Feldhofer M, 2007. Power and EM Attacks on Passive 13.56 MHz RFID Devices, Graz University of Technology.

61. Çiftçibaşı E, 2009. RFID Sistemlerde Güvenlik Açıkları ve Çözüm Yolları. TMMOB, 437: 9192.

62. Boer Bilişim A.Ş. http://boer.com.tr/tr/cozum-155-0-havaalani-ve-hava-yollari.asp, (Erişim Tarihi: 24.04.2015).

63. Aybil Bilişim. Gerçek Zamanlı Yer Belirleme. http://www.aybilbilisim.com.tr/asp/index.asp?frmkodu=urun.asp?bno=35!dil=Tr!Sayfa=Ger\%E7 ek\%20Zamanl\%FD\%20Yer\%20Belirleme, (Erişim Tarihi: 24.04.2015).

64. Leena T, Swetha AJ, Seril J, Arya K, Tedik N, Obang P, 2014. Automatic Speed Control of Vehicles Using RFID. International Journal of Engineering and Innovative Technology (IJEIT), 3 (11): 118-120.

65. Li Z, Rajit G, Prabhu B, 2004. Applications of RFID Technology And Smart Parts In Manufacturing. Salt Lake City.

66. Oylum Tekstil Elektronik LTD. ŞTİ. http://www.teknopalas.com.tr/cozumler/. (Erişim Tarihi: 23.10.2015).

67. Akın A, 2014. Türkiye'nin RFID Merkezi. http://www.rfidturkey.com. (Erişim Tarihi: 22.05.2014).

68. Pala Z, İnanç N, 2007. Smart Parking Applications Using RFID Technology. Smart Parking Applications Using RFID Technology, Istanbul.

69. Özpınar A, Kazasker E, Öz Ö, 2010. Akıllı Trafik Denetimi ve Yönetimi için RFID ile Elektronik Plaka Uygulaması. Akademik Bilişim, Muğla.

70. Pala Z, 2008. RFID Teknolojisi ile E-Sınav Uygulaması. Akademik Bilişim, Çanakkale.

71. Zahir AM, Prashant HM, Dwija G, Akshay D, 2013. Traffic Signal: Control \& Management (ZigBee/RFID).

72. Lionel M, Liu Y, Yiu CL, Abhishek PP, 2004. LANDMARC: Indoor Location Sensing Using Active RFID. Kluwer Academic Publishers.

73. Tuğaç B, Kavas A, 2007. Radyo Frekans Kimlik Tanıma Sistemleri ile Elektronik Para Uygulamasının Gerçeklenmesi. III. İletişim Teknolojileri Ulusal Sempozyumu, Adana.

74. Tan O, Korkmaz İ, Gidiş O, Uygun S, 2009. Hasta Takip Sistemlerinde RFID Uygulaması. XI. Akademik Bilişim Konferansı Bildirileri, Şanlıurfa.

75. Vikipedi. Hizlı Geçiş Sistemi. Ekim, 2014. http://tr.wikipedia.org /wiki/H\%C4\%B1zl\%C4\%B1_Ge\%C3\%A7i\%C5\%9F_Sistemi. (Erişim Tarihi: 25.10.2014).

76. Pala Z, 209. RFID Teknolojisinin Acil Müdahelede Kullanımı. Akademik Bilişim. p. 3. Şanliurfa.

77. Vikipedi. NFC. http://tr.wikipedia.org/wiki/NFC. (Erişim Tarihi: 26.10.2014).

78. NXP Semiconductors. NFC Everywhere. http://www.nxp.com/techzones/nfczone/overview.html. (Erişim Tarihi: 26.10.2014). 
79. Souvik S, Subhashis R, Subir KS, 2014. A Proposal for Enhancing Museum Visiting Experience Implementing Active RFID Technology. 2014 Fourth International Conference on Advances in Computing and Communications, Cochin.

80. Ünal U, 2011. RFID ile Gerçek Yaşam Bağlantıs1. http://www.halklailiskiler.com.tr/RFID_ile_gercek_yasam_baglantisi.php. (Erişim Tarihi: 28.10.2014).

81. Vary J, 2014. John Lewis Store to Furnish Its Customers. RFID Journal. pp. 1-3.

82. Das R, Harrop DP, 2015. IDTechEx. RFID Forecasts, Players and Opportunities 2016-2026. http://www.idtechex.com/research/reports/rfid-forecasts-players-and-opportunities-2016-2026000451.asp. (Erişim Tarihi: 25.10.2015).

83. [83] IDTechEx, 2014. Passive RFID grows by 1.12 billion tags in 2014 to 6.9 billion. http://www.idtechex.com/research/articles/passive-rfid-grows-by-1-12-billion-tags-in-2014-to-69-billion-00007031.asp. (Erişim Tarihi: 31.10.2014).

84. Üstündağ A, 2008. RFID ve Tedarik Zinciri, RFID İTÜ Research and Test Center.

85. Vikipedi. 2015. Magnetoresistive random-access memory. https://en.wikipedia.org/wiki/Magnetoresistive_random-access_memory. (Erişim Tarihi: 23.10.2015).

86. O’Connor MC, 2006. Weyerhaeuser Acquires Tag Innovator Organic ID. RFID Journal

87. Önal M, 2013. Gömülü Sistemler İle RFID Mimarisi ve Programlama, 1. Bask1. cilt I, Kodlab Yayın Dağıtım Yazılım ve Eğitim Hizmetleri San. ve Tic. Ltd. Şti., pp. 6-7.

88. Abdelhalim MB, El-Mahallawy M, Elhennawy A, 2012. Design \& Implementation of an Encryption Algorithm for use in RFID System. International Journal of RFID Security and Cryptography (IJRFIDSC), 1: 1-4.

Geliş Tarihi: 02/11/2015

Kabul Tarihi: 19/11/2015 